\title{
Sound-as-Art
}

\section{The Rise of the Corporeal and Noise in Twentieth-Century Art Practice}

\author{
Chris Black
}

\begin{abstract}
A thesis
submitted to Massey University and Victoria University of Wellington in fulfilment of the requirements for the degree

Master of Music in Composition

New Zealand School of Music
\end{abstract}

2012 


\begin{abstract}
This thesis explores the relationship between human corporeality, space, sound and noise in twentieth-century art. The thesis introduces some novel concepts, notably that corporeality, noise and the notion of an expanded field form the bedrock of contemporary sound-based art practice, or what the author refers to as sound-asart. The terms Corporeal Sound Art and Non-Corporeal Sonic Art are introduced as a way to highlight the traditional distinction between corporeally inclusive sound art and corporeally exclusive acousmatic music. Ultimately, this thesis extols extramusical elements in the realization of sound-based artwork and champions human corporeality and noise as central concerns for sound artists and sonic artists in our current age of digital mediatization.
\end{abstract}




\section{ACKNOWLEDGMENTS}

First and foremost I would like to thank my academic supervisor Dr Dugal McKinnon. His in-depth knowledge, approachability, and saintly patience in the face of all manner of (often inane) questions put to him by yours truly, was nothing short of remarkable. I would like to thank some inspirational people who influenced me during my time at Victoria University. They include Michael Norris, Paul Doornbusch, John Psathas, Lissa Meridan, Allan Thomas, Rebecca Rice, David Maskell, and Phyllis Mossman. In particular I wish to thank my fellow sonic art students for providing feedback and practical support regarding my creative portfolio. They include Samuel Walker and Michael Hobbs for filming, Richard Robertshawe for collaborating on Magnetic Picnic, and Bridget Johnson for her positive support down the home stretch. I make special mention of Jason Wright for his invaluable contribution in the filming of performances, technical set-up for live performances, and audio mastering assistance. And last but not least, I would like to thank my family, who have been a constant source of support and encouragement throughout my time at University. 


\section{CONTENTS}

Introduction

p. 1

CHAPTER 1

Noise and the Corporeal in Futurist and Dadaist Performance

p. 7

CHAPTER 2

The Expanded Field and the Corporeal in Russian Futurist Theatre and the Bauhaus School p. 13

CHAPTER 3

Sound-as-Art—Expanding the Aural Field p. 19

CHAPTER 4

Sound-as-Idea p. 27

CHAPTER 5

Non-Corporeal Sonic Art versus Corporeal Sound Art p. 33

CHAPTER 6

Real-time External Processing and the Emergence of the

Performance Art Genre p. 40 
CHAPTER 7

The Age of Digital Enhancement .............................. p. 48

CHAPTER 8

Corporeal Relevance in the Age of Digital Mediatization .............. p. 56

Conclusion .................................................. p. 67

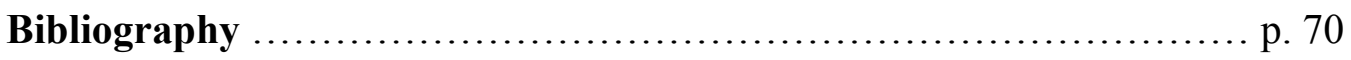

$* * *$

Creative Portfolio ................................................. p. 74 


\section{INTRODUCTION}

This thesis investigates the development of sound-as-art in twentieth-century experimental art practice. Sound-as-art refers to the use of non-musical sound for artistic purposes. This term is intended to be inclusive of corporeal influence and noise. Sound-as-art is to be seen as opposed to the field of music, which traditionally views both the corporeal and noise as contaminants to its goal of worldly transcendence. By contrast, corporeality and noise are regarded as fundamental to the sound-as-art experience. This thesis attributes the rise of soundas-art to three historical developments in twentieth-century art:

1. The acceptance of noise as an art material.

2. The inclusion of corporeality as an art material.

3. The emergence of an expanded field of activity.

Consequently the core principles that define the sound-as-art approach to art making and art appreciation—noise, corporeality, and the expanded field-make up the three main discussion points of this thesis. These three fundamentals, referred to in totality as the sound-as-art trivium will be elaborated on and developed throughout.

The terms noise, corporeality, and the expanded field have a particular meaning within the context of this thesis. I regard noise as any sound that is disruptive of, or 
counter to, musical form. ${ }^{1}$ The term corporeal is used in this body of work to signify the physical human body. This should not be confused with the broader meaning of the term, which may refer to any physical substance or matter. The expanded field requires a more detailed explanation and will be defined by the following:

1. The field is inclusive of human bodies and all sound.

2. The field is ecological, consisting of multifarious relationships.

3. The boundaries of the field are non-definitive. The field itself has no centre. The frame of the field is one of flux, open to individual interpretation.

4. The field is both physical and conceptual.

Points 3 and 4 take their influence from the expanded field as defined by Rosalind Krauss (1979) in her seminal work "Sculpture in the Expanded Field". ${ }^{2}$ In this essay Krauss expands the traditional definition of sculpture, applying the term expanded field to describe the expanded contextual situation of postmodern sculpture. For example Krauss states that the boundaries of contemporary sculpture emanate beyond the explicit object, and that the environment is all-important in giving form to an artwork. Such perceptions resonate with the expanded field as articulated in the four-point definition above. However, Krauss does not mention the aural field as part of her discussion. Therefore, I have emphasized the role of noise and corporeality (see point 1), which is absent in Krauss. The expanded field, as far as sound-as-art is concerned, is to be considered an adaptation of Krauss'

\footnotetext{
1 That is not to say that noise as a compositional element is not intentionally used by some composers in musical composition, merely that this thesis heralds noise as an alternative starting point for sound-based art work, wherein a musical outcome is not necessarily the primary goal.

2 Krauss, Rosalind. "Sculpture in the Expanded Field", October (Vol 8 (Spring) 1979, pp. 30-44)
} 
expanded field for the benefit of a sound-based thematic.

Throughout this thesis I will be referencing artistic activities that accept the physical human body as being part of the aural field. This can be either in a performance or recording capacity. Marina Abramovic's Rest Energy (performance, 1980) and Alvin Lucier's I Am Sitting in a Room (recording, 1969) are two examples. Both of these artworks I regard as corporeal in that they intentionally allow for the indeterminate noisy activity of an expanded environment inclusive of human corporeality. Having said this, what this thesis is primarily attempting to do, is credit the performative mode, as playing a vital role in the historical development of contemporary sound art, where the ambiguous nature of the corporeal is celebrated and seen as a fertile site for formulating new languages involving the human body, noise and its relationship to its environment.

I will be drawing on research and work from a range of artistic disciplines including sound art and sonic art, theatre, visual art, body art and performance art. In order to appreciate sound-as-art, a parallel investigation of the sonic, the corporeal, and the extramusical within the general art world is necessary. To delve into one discipline inevitably leads one to find correlations with other arts practices.

The notion of the visual arts as playing an important role in the development of sound art has been given credence in recent times by authors such as Douglas Khan, Seth Kim-Cohen, and Chris Salter. What this thesis adds to this crossdisciplinary conversation between the visual and the sonic is the notion of the 
corporeal as playing an equally important role in the maturation of the sonic in contemporary art.

A brief summary of each chapter is as follows:

Chapter 1, 'Noise and the Corporeal in Futurist and Dadaist Performance', discusses the foregrounding of noise and corporeality through the art of the Futurists and Dadaists. Topics discussed include Luigi Russolo's The Art of Noises and avant-garde performance poetry.

Chapter 2, 'The Expanded Field and the Corporeal in Russian Futurist Theatre and the Bauhaus School', introduces the spatial aspect of the expanded field in reference to Russian Futurist and Bauhaus theatre practices.

Chapter 3, 'Sound-as-Art_Expanding the Aural Field', introduces the aural aspect of the expanded field. John Cage's 4'33" (1952) is discussed and referenced as an example of the sound-as-art aesthetic. The art of Alan Kaprow and La Monte Young is alluded to.

Chapter 4, 'Sound-as-Idea', delves into the conceptual aspect of the expanded field. The artwork of Fluxus is discussed whilst the sculpture Box with the Sound of Its Own Making (1961) by Robert Morris is put forward as an example of conceptual sound-as-art. 
Chapter 5, 'Non-Corporeal Sonic Art versus Corporeal Sound Art', focuses on the acousmatic as a musical alternative to sound-as-art. The terms Corporeal Sound Art and Non-Corporeal Sonic Art are introduced as a means to describe the two ideological streams that helped define sound in the arts during the later half of the twentieth-century.

Chapter 6, 'Real-time External Processing and the Emergence of the Performance Art Genre', examines external processing in relation to sound-based experimental art collectives. Body-based art and the body-centred philosophy of Maurice Merleau-Ponty is discussed.

Chapter 7, 'The Age of Digital Enhancement', claims the decade of the 1980s as a foregrounding period for non-corporeal sonic art. Machine-body hybrids are highlighted in reference to the performance artists Stelarc and Laetitia Sonami. The research of Phillip Auslander is discussed.

Chapter 8, 'Corporeal Relevance in the Age of Digital Mediatization', discusses the notion of corporeal desire through corporeal absence. The chapter argues for the relevance of the corporeal within the context of a digitally mediatized culture.

I would like to take a moment to describe what this thesis is not. It is not an exhaustive account of the history of sound in the arts. It focuses on human corporeality in relation to the sonic. While realizing the instrumental role that technology has played in shaping twentieth-century art practice, this thesis focuses on the application of the physical human body in sound art and sonic art 
performance and will deal with technology only as it relates directly to the corporeal. Finally, I would like to warn the musically trained reader that what follows is an investigation of sound-as-art as opposed to sound as music. I encourage the reader (particularly if they are musically trained) to try and put to one side preconceived notions of musicality and the musical in order to properly enter into the spirit of this thesis topic. In an attempt to condition oneself to begin this journey, the following quote from John Cage appropriately sets the scene for what lies ahead.

One need not fear about the future of music...But this fearlessness only follows if, at the parting of the ways, where it is realized that sounds occur whether intended or not, one turns in the direction of those he does not intend. This turning is psychological and seems at first to be a giving up of everything that belongs to humanity - for a musician, the giving up of music. This psychological turning leads to the world of nature, where, gradually or suddenly, one sees that humanity and nature, not separate, are in this world together; that nothing was lost when everything was given away. In fact, everything is gained. ${ }^{3}$

\footnotetext{
${ }^{3}$ Cage, John. Silence (Middleton, Connecticut: Wesleyan University Press, 1961) p. 8
} 


\section{CHAPTER 1}

\section{Noise and the Corporeal in Futurist and Dadaist Performance}

With the advent of Futurist and Dadaist performance during the first two decades of the twentieth-century, the material body of the performing artist emerged as a potent medium for the articulation of modernist ideas. Coupled with this foregrounding of the corporeal, the Futurist artist Luigi Russolo would give aesthetic credence to the industrial sounds of the era by promoting noise as a legitimate sonorous material for art making. Given the importance of Russolo's work, I will begin this chapter by briefly discussing it, as his vision forms a locus, which the often-raucous performance art of the Futurists and Dadaists can be linked to. I will then discuss the performance poetry of Futurist and Dadaist artists, and highlight how, through their performances, noise and body were used as a means to radicalize traditional syntax and phonetics.

During the early decades of the twentieth-century, the noises of industrial machinery and the populous urban environment proved extremely influential for avant-garde artists, none more so than for the Futurist artist Luigi Russolo. In 1913 Russolo published his seminal manifesto The Art of Noises. In this manifesto Russolo champions the sounds of the everyday, advocating mechanical noise as valid compositional material. Russolo heralded noise as a solution to what he regarded as the unsuitability of classical instruments to adequately communicate 
the concerns of the industrial age. ${ }^{4}$ The practical aspect of the manifesto was Russolo's creation of mechanical noise-making machines or intonarumori (lo-tech devices consisting of moving parts requiring human operation). These machines were constructed with the aim of imitating the noises of the urban environment.

Russolo is regarded as the all-important catalyst for raising the profile of noise as a legitimate artistic material. His manifesto and the intonarumori can be considered the beginning of a noise culture, expanding away from the pitch-articulating function of acoustic instruments within the Western art music tradition, toward a practice based in noise and sonic complexity.

In its day Russolo's manifesto attracted few advocates from within the musical fraternity. Nevertheless, some musical composers did take Russolo's ideas to heart. For example, everyday sounds were incorporated by Erik Satie in Sergei Diaghilev's ballet production Parade (1918) in which noise making items such as a typewriter and a foghorn were used. Although there were other individuals who adopted Russolo's ideas within the context of classical composition, the musical community mainly looked to the reconfiguring of notational systems as heralding the promise of a new music. ${ }^{5}$ This is exemplified by the reverential attitude shown

4، ...musical sound is too limited in its qualitative variety of tones. The most complex orchestras boil down to four or five types of instrument, varying in timbre: instruments played by bow or plucking, by blowing into metal or wood, and by percussion. And so modern music goes round in this small circle, struggling in vain to create new ranges of tones. THIS LIMITED CIRCLE OF PURE SOUNDS MUST BE BROKEN, AND THE INFINITE VARIETY OF 'NOISE SOUND' CONQUERED.' Extract from The Art of Noises by Luigi Russolo. Published as a booklet by Direzione del Movimento Futurista, Milan, 1 July 1913. Sourced from Apollonio, Umbro. (ed.) Futurist Manifestos (London: Thames and Hudson, 1973)

\footnotetext{
${ }^{5}$ The American composer George Antheil was another individual who employed everyday items in the production of sound - his use of airplane propellers in Second Sonata - "The Airplane" (1923) for example.
} 
toward Arnold Schoenberg's twelve-tone serialism. The serialist approach was an expansion of an existing musical system, far removed from the more radical suggestion advanced in Russolo's manifesto.

By contrast, Russolo's Futurist colleagues empathized with his passion for the noises of industry and incorporated noise into their performance-laden activities. Formed in 1909 the Italian Futurist movement was driven by an unbridled enthusiasm for modern technology. Futurist artwork evoked notions of mechanization, dynamism, speed and violence, and performance as a mode of delivery emerged as an appropriate vehicle to express these themes. Futurist performances took many forms including theatre plays, operas, ballets, music, and performance poetry.

The founder of Futurism, Filippo Tommaso Marinetti, recognized the potential of noise as a way to invigorate performance poetry. Marinetti, with a background as a symbolist poet, aimed to empower language by expanding its expressive parameters beyond the semantic meaning of the written word. Instead, he aimed to stress the importance of how words sound. Akin to Russolo, Marinetti sought to infuse his work with the sounds of everyday life. With Marinetti's approval, the intentional interjection of noise elements during acts of vocalization became part and parcel of Futurist poetry readings. Thus, for Futurist poets the sonorous delivery of scripted texts became paramount to the completion of the poetic work. This new importance given to the performative aspect of the written word served to elevate noise as a compositional tool while placing focus on the corporeality of the artist as a sounding performer, rather than as a writer of silent texts. 
Continuing on from the performance poetry of Marinetti, as well as Russolo's advocacy of noise as compositional material, Dada (founded in 1916) would further cement the artists' body and noise as vital tools for art making. The use of chance, readymades, multidisciplinary activity, and a newly configured relationship between performers and audiences, were just some of the innovations explored by the Dadaists. The theme of technology was not as strongly pursued in Dada as it was within Futurism. Dada arose amidst the chaos of World War I. The war had revealed the destructive side of mechanization, which served to pacify the radical enthusiasm toward technology so vocally expressed by the Futurists.

Of more importance to the Dada aesthetic was their interest in Primitivism, which celebrated the art of non-Western cultures. Noise making was a prominent feature of Dadaist performance, so much so that the term bruitism was coined to categorize this activity. ${ }^{6}$ As with the Futurists, Dadaist performance poets intentionally injected noise elements into their work seeking to distort and challenge literary convention. Although Russolo's The Art of Noises drew its inspiration from modernist mechanization, the manifesto's disregard for traditional Western musical systems was complementary to the idea of Primitivism. The following quote from Dada protagonist Hugo Ball from 1916 regarding a simultaneous poetry reading involving three performers, gives some sense of the Dadaist enthusiasm for phonetic enhancement and sonic discord:

All the styles of the last twenty years came together yesterday...three or more voices speak, sing whistle, etc., at the same time in such a way that the elegiac, humorous, or bizarre content of the piece is brought out by these combinations... Noises (an rrrrr drawn out for minutes, or crashes, or sirens,

\footnotetext{
${ }^{6}$ Kahn, Douglas. Noise, Water, Meat: a History of Sound in the Arts (Massachusetts: MIT Press, 2001) p. 45
} 
etc.) are superior to the human voice in energy. ${ }^{7}$

This strategy of using noise as a way to invigorate and punctuate human speech represents the artist's body and sound coming together in an attempt to express raw emotion, unrefined through its translation into linguistic form. Sound poetry, with its two transgressive elements of the artist's body exposed and noise, went against European artistic convention and offered the untrained artist a style of delivery that was immediate and hard-hitting. Its understanding required no intellectual prompt because there was nothing literal to interpret. Bruitism as action was the message.

What we find in Futurist and Dadaist performance poetry is that noise is intentionally assimilated into the performative act as a means to energize artistic expression. Furthermore, these noise elements are given voice through the medium of the performing body, thereby foregrounding the corporeal. In contrast to experimental classical composers such as Erik Satie, who combined noise elements within the context of an orchestral ensemble, the type of noise that the avant-garde performance poets used had its origins in the non-instrumental corporeal. In a sense, this entails a return to the body, which historically, has long been a prominent subject within the fine arts as evidenced in portraiture and sculpture, even as it was excluded as a focal subject within the musical arts. In the twentiethcentury, as many artists begin to take on the role as the actor in projecting their art via performance, the artist is put forward as the living art subject in place of the art object. Scholar and theatre practitioner Nina Hein describes this phenomenon as

${ }^{7}$ Kahn (2001) p. 49 
'the eradication of the duality between creator and performer' ${ }^{8}$ She alludes to the Dadaist performance evenings as the historical period when the persona of the artist is revealed, as the body itself is foregrounded. To paraphrase Hein: the author, actor, and text congeal to form a holistic ephemeral work of art.

In bringing noise and the corporeal into artistic focus we are provided with two of the three fundamentals that make up the sound-as-art trivium. The next chapter will introduce the third fundamental, that being the expanded field while continuing to trace the rise of the corporeal as a subject for art.

${ }^{8}$ Hein, Nina. 'Body Imagery in the avant-gardes of the twentieth century' Body, Space and Technology Journal (Vol 9 (2) 2010, p. 2) 


\section{CHAPTER 2}

\section{The Expanded Field and the Corporeal in Russian Futurist Theatre and the Bauhaus School}

This chapter will venture into the third fundamental of the sound-as-art triviumthe expanded field. This field aspect of sound-as-art refers to both the field of activity in which the artist operates and the spatial field in which the artwork exists. During the 1920s the Russian strain of Futurism and the Bauhaus School would draw attention to the expanded field through the development of kinetic scenography and multi-media theatre. Through this activity, the idea of an expanded field consisting of multifarious relations and shifting borders was ventured into. The Russian sphere of influence also made huge strides in promoting the human body as a metaphor for modernist mechanization. This, in turn raised the idea of the physical body as an expressive totality.

Generally speaking, during the 1920s and 1930s the Russian theatrical view of corporeality revolved around the expressive qualities of body movement combined with a Futurist interest in mechanical action. Russian Futurism ushered forth a theatrical style based on physicality in which the body of the performer was to be trained in its entirety. This was different to that of the avant-garde performance poets, for whom sonorous vocalization was the prime focus of bodily function.

The emphasis on physicality in Russian Futurist theatre is evidenced by the proliferation of body training systems that developed from within their ranks. 
Biomechanics created by the Russian director Vsevolod Meyerhold was one such system that proved extremely influential. Meyerhold's biomechanics was made up of a series of physical exercises, influenced in part by the mechanical efficiency of industrial technology. Fellow director Nikolai Foregger took the metaphorical view of the mechanized human form to the extreme in his production Dance of the Machines from 1924, in which his actors literally played the roles of mechanical gears and levers. A description of Foregger's production according to one critic reads:

...bodies became correctly constructed appliances. They no longer moved, they functioned... Dancing is intended to be nothing but a vivid demonstration of the adequate organization of the human machine. ${ }^{9}$

Meyerhold's and Foregger's advocacy of mechanical imitation exemplifies the Futurist obsession (played out in the work of both the Russian and Italian Futurists) with the human body as a metaphor for modernist mechanization.

Of significance to my study, in light of the expanded field, is the intentional melding of this machine inspired body with the infrastructure of the mechanical stage. In the 1922 production The Magnanimous Cuckold, directed by Meyerhold, designer Lyubov Popova created a large-scale set representing the inner workings of a machine complete with moving parts. Meyerhold developed his choreography in collaboration with the kinetic environment with the biomechanical actions of his actors melding intentionally with the scenography.

The idea of expanding the possibilities for actor/audience interaction was also

\footnotetext{
${ }^{9}$ Gordon, Mel. 1975. Foregger and the Dance of the Machines. TDR 19, no.1 (March): 68-73, from p72) sourced from Salter, Chris. Entangled: Technology and the Transformation of Performance (Cambridge, Massachusetts London: MIT Press, 2010) p. 233
} 
explored. This is exemplified in El Lissitsky's stage design for Sergei Tretyakov's play I Want a Child from 1929 (also a project Meyerhold participated in). The scenic architecture was devised in the round and was intended to blur the boundaries between audience and performance space. The set was to consist of ramps and platforms that seamlessly melded into the audience space. ${ }^{10}$

Innovative set designs by scenographic pioneers such as Popova and Lissitsky looked to break down the traditional audience/stage relation - the proscenium arch paradigm — where the audience is given only one perspective on the dance/drama. This gradual inching toward a de-centralization of performance space through set design and innovative dramaturgy leans toward the idea of opening oneself up to a multifarious field that extends beyond the confines of the conventional stage. Such experimentation signals an important shift toward the notion of an expanded field.

As a complement to the spatial preoccupations of Russian scenographers, the Bauhaus school in Weimar Germany, founded by Walter Gropius in 1923, emerged as an artistic centre, where, as with the Futurists, technology was held in high regard. Bauhaus associate Laszlo Moholy-Nagy cleverly employed mechanical scenography (often in combination with lighting effects) in the creation of kinetic performance spaces. Moholy-Nagy's design Kinetic Construction System, created in collaboration with Alfred Kemeny, is an example of the artist's interest in fluid architecture. The design is cylindrical in shape and consists of conveyor belts on which the actors are intended to enter and exit the performance

\footnotetext{
${ }^{10}$ Despite plans and models being drawn up for this set design, the set was never constructed.
} 
space. In this design various architectural features are configured to move simultaneously, while the entire structure moves perpetually in a circular motion.

Oskar Schlemmer, for whom the human body was a focal subject, was another Bauhaus innovator who experimented with altering audience perception of space. Schlemmer's bodily and spatial illusions were achieved through a subtle combination of multiple bodies in space, abstract geometric costumes, and colorful stage sets. His intention was to transform the body, rather than simply project the body in imitation of something mechanical. ${ }^{11}$ According to Chris Salter, Schlemmer differs from choreographers such as Meyerhold and Foregger in that he succeeded in, "physically extending the human body through simple technologies into space itself. ${ }^{12}$

The role of technology cannot be overlooked regarding the Russian Futurist and Bauhaus attempts to augment and distort audience perception of theatrical space and body form. In many cases the application of technology was of primary importance to the creative process. For example, the scenographic projects mentioned above (with the exception of Schlemmer) were all made possible via machine-based technologies. What I find admirable within the avant-garde activity of the 1920s and 1930s, as evidenced in the works cited above, is that technology is seen to complement somatically-based theatre practices. Although technology in

\footnotetext{
${ }^{11}$ Dancers such as Loïe Fuller had previously attempted to augment the body through simple technologies, however the attention Schlemmer pays to the relationship between multiple bodies and objects and their ability to define space is what is important in this instance. Schlemmer unmistakably focused on the body as a new artistic medium and was particularly interested in using the body as a means to explore spatial relation.

${ }^{12}$ Salter, Chris. Entangled: Technology and the Transformation of Performance (Cambridge, Massachusetts London: MIT Press, 2010) p. 234
} 
the form of electric stage lighting and ever more complex mechanical scenography was used to increasing effect, technology succeeded in altering our perception of body and space without dispensing with the important role of corporeal presence.

It is also important to note that the more-or-less universal acceptance of the body as a metaphor for mechanical efficiency in Futurist theatre, points to an underlying curiosity for a technologically mediated body. The practical application of human body fused with hard-wired technology would come to fruition during the 1980s and 1990s. The theme of a technologically infused body will be discussed at length in chapters 7 and 8 .

In the work of both the Russian Futurists and the Bauhaus, we see developments that anticipate sound-as-art in relation to the expanded field. Through their spatial innovations the artists associated with these movements questioned the traditional notion of art as taking place within the confines of a static framework. What we see emerging out of this intensely creative period initiated by the Russian avantgarde and the Bauhaus is a gradual shift in attention toward the conception of performance space as a site for diverse media, surrounding and extending the body and the stage. The understanding that an artist works in a field of multifarious relations, inclusive of human corporeality, combined with the realization that the boundaries of the performance space are non-definitive, paves the way for the expanded field to develop fully.

This chapter has focused on the spatial aspect of the expanded field. The next chapter will address the sonic dimension of the expanded field. This is also where 
we cross over into the second half of the twentieth-century. The first half of the century cemented noise, body, and the expanded field as themes within the avantgarde. It is during the 1950 s and 1960 s that sound-as-art (i.e. noise, corporeality, and the expanded field in combination) will be fully realized. It is also to the music world that we now turn as noise raises its head as chief agitator for a very important figure in the sound-as-art story-John Cage. 


\section{CHAPTER 3}

\section{Sound-as-Art-Expanding the Aural Field}

This chapter focuses on the American sphere of influence regarding the development of sound-as-art during the 1950s and early 1960s. I will introduce John Cage and discuss Cage's seminal composition 4'33". This composition is significant as it is one of the first examples of an artwork that articulates the soundas-art trivium. I will then go on to discuss some of Cage's influences and briefly touch on the work of two of Cage's students, Alan Kaprow and La Monte Young. I will reference several works by Kaprow and Young that strongly resonate with the idea of an expanded field inclusive of noise and corporeality.

John Cage was a classically trained musical composer who forged a very distinctive path, separate from that trodden by most composers in the twentiethcentury. His philosophical outlook was influenced by oriental thought as much as occidental. Furthermore, he was not averse to incorporating ideas from other arts disciplines into his compositional practice. In Cage's compositions and writings from the 1950s onwards we can detect the defining threads of indeterminacy, multi-disciplinary activity and the blurring of art with real-life situations.

Almost single-handedly, Cage was responsible for expanding the aural field of musical composition to include all sounds, even sounds that the composer does not intend. If one is to adopt the expanded field as a construct for creative process and aesthetic reception then the totalization of the aural field must include all sounds. 
Cage's iconic composition 4'33" (1952) articulates the composer's attitude that all sounds can be considered music. 4'33" has been widely detailed and discussed in many publications so I do not feel the need to describe the piece in depth here, suffice it to say, that one of the main intentions of the composition was that audience attention would be directed toward the ambient sounds of the performance environment. By doing this, Cage expanded the field of creative activity beyond the confines of the stage, opening up the audience to a multifarious field of sonorous activity. Such activity includes noises sourced from the material bodies of the audience. Whether sounds made by the audience are intentional or not, for the discerning listener, these incidental noises signalling corporeal presence are all part of the expanded aural field.

A by-product of the acceptance of an indeterminate field, in which bodies are present, is that the audience is brought into play as contributors to the sonic outcome. Audience participation subverts the composer's traditional authorial role. This idea of downplaying authorial intentionality would be most famously articulated by Roland Barthes in 1968 with the publication of his seminal essay The Death of the Author in which he declares that a reader of literary text is the primary determiner of meaning rather than the author. ${ }^{13}$ With Cage expanding the field of sonorous activity beyond the stage, the audience become contributors to the work. In the following quote from 1965 Cage expresses the important role bequeathed to the spectator/listener as interpreter:

...the less we structure the theatrical occasion and the more it is like unstructured life the greater will be the stimulus to the structuring faculty of

\footnotetext{
${ }^{13}$ Barthes, Roland. The Death of the Author (1967) published in Critical Essays (trans.) Richard Howard (Evanston [III], Northwestern University Press, 1972)
} 
each person in the audience. If we have done nothing, he then will have everything to do. ${ }^{14}$

Cage's reference to the 'theatrical occasion' in the above citation had a particular meaning for him, for he adopted the word theatre to describe the simultaneous effect of both aural and visual stimuli on ones perception of a performance event. As Cage states:

Theatre is all the various things going on at the same time. I have noticed that music is liveliest for me when listening for instance doesn't distract me from seeing. ${ }^{15}$

Cage was influenced by playwright Antonin Artaud's theoretical treatise The Theatre and Its Double, an essay in which the writer advocates a theatre not based on text but on the multitude of activity played out within a de-centralized performance space. ${ }^{16}$ Artaud sought to immerse the spectator in the theatrical event by bringing them into the centre of the action. Cage referenced The Theatre and Its Double in describing his strategy for his multi-media production Black Mountain Piece from 1952. This performance, to which the diverse talents of Robert Rauschenberg, David Tudor and Merce Cunningham contributed, involved numerous activities played out simultaneously. As Cage attests when discussing this work in an interview from 1974:

We got the idea from Artaud that theatre could take place free of text, that if a text were in it, that it needn't determine the other actions, that sounds, that activities, and so forth, could all be free rather than tied together...so that the audience was not focused in one particular direction. ${ }^{17}$

\footnotetext{
${ }^{14}$ Sandford, Mariellen R. (ed.) Happenings and Other Acts. New York: Routledge, 1995, p. 55

${ }^{15}$ Cage (1961) p. 149

${ }^{16}$ Artaud, Antonin. The Theatre and Its Double: Essays, (trans.) Victor Corti (Montreuil; London: Calder, 1970)

${ }^{17}$ Cage in interview with Mary Emma Harris, 1974, quoted in Kostelanetz, Conversing with Cage, p. 104. Sourced from Gann, Kyle. No Such Thing as Silence (New Haven: Yale University Press, 2010) p. 155
} 
The purpose behind this de-centralization of space through the intentional subversion of text, freed one to focus on the disparate nature of other activities happening within the space. The seating for the audience was arranged so that no single point of focus was implied. In this way, the spectator/listener became the centre of the work, responsible for creating meaning out of a multiplicitous experience.

Returning to Cage's 4'33"- -in this composition we witness an emerging consciousness of an expanded field, a field referring to more than music and more than sound, echoing Artaud's more than text as a rejection of a traditional theatre based on script. Cage's promotion of all sound and more importantly his theatrical stance opened up the performing arena to encompass a multifarious field of activity. This notion of a multifarious expansive field would signal the allimportant turning point, from the experimental practice of using noise within a musical framework (i.e. Erik Satie's Parade), toward an evaluation of noise as part of an extramusical field of relations.

The attention given to an expanded field was not lost on Cage's students who, whether involved in visual art or sound-based art, applied the idea of an expanded field in creating novel and experimental performance constructs. Many of Cage's students would emerge to be major players in the experimental arts. Alan Kaprow and La Monte Young were two students of Cage who would make valuable contributions to performance art and sound art respectively. 
Kaprow embraced indeterminacy and extended Cage's theatre by attempting to intentionally stimulate all the human senses, not just hearing and sight. Taking inspiration from Cage's Black Mountain Piece, Alan Kaprow instigated a programme of performances he termed Happenings beginning with the work 18 Happenings in 6 Parts in 1959. Happenings allowed for performer and audience to inhabit the same unbounded space; a space in which multiple rehearsed situations were played out. Happenings gained traction as a cutting-edge mode of performance throughout the 1960s.

Composer La Monte Young also furthered Cage's indeterminacy and theatre exemplified by his Composition 1960 \# 5 (1960) in which butterflies are released into a room with the piece ending when the butterflies have left the room. In another Young composition, Composition 1960 \# 4 (1960), the audience unknowingly compose the piece during the performance. To paraphrase Young's instructions, the audience are told the duration of the piece, the lights are then turned off, placing the audience in darkness. After the pre-announced timing of the piece has passed, the lights are turned on again. The audience is then informed that the piece has ended and that they themselves are the authors of the work. The ambiguity of the singular, stripped-back event served to entice the spectator further into the realm of individual interpretation. A third work of Young's Dream House (1962) very much relies on the movement of human bodies within a defined space. Dream House, which has survived to this day as a permanent installation, consists of a series of rooms in which audible frequencies reside. As visitors navigate through the rooms their physical bodies moving through the space alter the 
harmonic overtones of the resonant frequencies. Participants are drawn to ponder on the role that their own bodies play in shaping sonic outcome.

In the work of Kaprow and Young, Cage's conception of the theatrical is very much evident. Importantly, noise and audience are not seen as contaminants to these performance works, but rather noise and audience corporeality are regarded as authentic elements in the real-life projection of such acts.

Whether one can define such works as musical or not is an interesting question to contemplate, not least because Cage himself never erred from describing his theatrical works as musical compositions. According to the Concise Oxford English Dictionary 'music' is defined as, 'the art or science of combining vocal or instrumental sounds (or both) to produce beauty of form, harmony, and expression of emotion. ${ }^{18}$ I would argue that much of Cage's output during the 1950s and 1960s including 4'33" leant more toward performance art than it did to music.

There is some irony in that Cage embraced the incidental sounds of the human body and introduced to the art world compositional strategies that would have been considered blasphemous to the musical establishment, yet he never strayed from using the word 'music' when describing his work. Perhaps his continued use of the word he saw as a way to legitimize his revolutionary teachings for an audience that had been culturally conditioned to listen in musical terms. ${ }^{19}$ In this sense it is

\footnotetext{
${ }^{18}$ Soanes Catherine, Angus Stevenson. (eds.) Concise Oxford English Dictionary Eleventh Edition (Oxford: Oxford University Press, 2004) p. 942

${ }^{19}$ However, if one understands the composer as someone who combines elements, irrespective of their traditional status as musical materials, then it is possible to understand Cage as a composer who through the expanded field, expands the notion of composition itself.
} 
telling that Cage attempted to attach his most infamous work 4'33" to the classical tradition, by scoring it in three movements (hinting at Sonata form) and giving it a set duration.

One of the challenges for sound art practitioners from the 1950s and 1960s was how to communicate to their audience - an audience conditioned to hear sound in musical terms - the multi-dimensional nature of sound as a sculptural material in relation to an acoustic and/or conceptual environment. ${ }^{20}$ In this sense the gallery arena provided an alternative audience that was relatively open to the idea of sound as a non-musical material.

Despite Cage seeing himself as part of a musical lineage, his students, many of who were not musically trained, felt no pull toward identifying themselves as musicians. In fact, one can detect a concerted attempt by some of Cage's students to distance themselves from the world of music. For example Kaprow stated that he was interested in noise, not music, calling himself a 'noisician'. ${ }^{21}$ Kaprow's instructions for the sound component in 18 Happenings in 6 Parts included:

"wild enduring noise," "brief sound of breathing...change to crackling almost pitchless rhythms," and "OLD MAN SCREAMS furiously turning wildly in all directions..."22

Kaprow's script of noises is reminiscent of avant-garde performance poetry where the sounds of speech and style of delivery are more important than linguistic

\footnotetext{
${ }^{20}$ Here I employ the term sculptural material to signify sound as a tool for articulating spatial concerns, as opposed to musical concerns. This sculptural quality of sound will be elaborated on in Chapter 6 in reference to external processing and aural architecture.

${ }^{21}$ Khan (2001) p. 275

${ }^{22}$ Allan Kaprow, "18 Happenings in 6 parts/the script," in Happenings, (ed.) Michael Kirby (New York: Dutton, 1965) pp. 53-66. Sourced from Khan (2001) p. 275
} 
meaning. Of particular interest is the instruction concerning the old man screaming as he turns, alluding to the theatricality of the ocular and the aural in combination. It is from this period where terms such as 'non-musical', as coined by George Brecht, begin to emerge as a way to describe the inclusivity of non-musical sonic elements into the field of art. ${ }^{23}$

What becomes apparent in what I understand to be the non-musical approach of artists like Kaprow and Young is an abandonment of musical constructs in the pursuit of a wider understanding of meaning for sound in the arts. Unsurprisingly then, it is in the fields of visual art and performance art where some of the most enthusiastic adherents of the sound-as-art approach can be found. As the following chapters will show, non-musical artists would prove instrumental in promoting sound-as-art as an alternative to experimentation involving the extension of existing musical systems. Furthermore, similar to the corporeal foregrounding in Futurism and Dada, the performative mode would continue to play its role of announcing this new vanguard to the wider public. The next chapter will shed light on the importance of the performance-oriented Fluxus movement and explain the vital role of the visual arts in cementing sound-as-idea as a concept. In discussing this concept I will reveal how the expanded field branches out beyond the physical into the conceptual.

${ }^{23}$ Joseph, Branden. W. Beyond the Dream Syndicate: Tony Conrad and the Arts after Cage (Brooklyn, New York: Zone Books, c2008) p. 88 


\section{CHAPTER 4}

\section{Sound-as-Idea}

Previous chapters have attempted to establish the expanded field as an important development for the realization of noise and the corporeal in the arts. Chapter 2 dealt with the expansion of one's perception of physical space. Chapter 3 dealt with the expansion of the aural field beyond a musical framework. This chapter will introduce a further aspect of the field, the concept of sound-as-idea. This term deals with the conceptual aspect of the aural field. Fluxus artists and visual artists had a sizeable hand to play in establishing this conceptual practice in which the idea of sound is viewed as more important than the act of listening itself. I will begin by discussing the Fluxus movement, who succeeded in emphasizing the conceptual through their performance activities.

The Fluxus movement (of which La Monte Young was a member) was a performance-based art movement that surfaced during the late 1950s. Fluxus performances were less theatrical than Kaprow's Happenings. Fluxus focused on highlighting the phenomenal encounter by setting up austere, minimal situations. Fluxus performances were renowned for their text-based scores, consisting of instructions that were general rather than definitive. This approach resulted in performances that were more open-ended than the rehearsed ad hoc assemblages that made up Kaprow's Happenings. 
By scripting bizarre action sequences and rule-bound situations, Fluxus performances tended to stir within the spectator/listener a deep insight into the present moment. One of the ways it sought to achieve this was by slowing down everyday actions, enticing audiences to peer into the minute details of simple phenomena. This led to Fluxus artists composing works where the sound material was barely audible. Drip Music (1959) by George Brecht is a case in point. The piece consists of the delicate sound of water droplets dripping from a faucet. Brandon La Belle points to the value of this piece by way of forcing the audience to listen attentively in quietude:

...the ear must move closer to the quiet sounds, to follow each drip, as a universe of potentiality, each single drip an event, each resonance a sonic revelation. To stage the near imperceptible was to direct an audience toward the phenomena of perception itself. ${ }^{24}$

The idea of employing sound on the cusp of audibility leads us to the more radical development of sound-as-idea. The notion of sound as an idea opens up an entirely new proposition for the use of sound in the arts. One can detect Brecht's hinting at this objective as he acknowledges Cage's theatre in the following quote:

I wanted to make music that wouldn't be for the ears. Music isn't just what you hear or what you listen to, but everything that happens. ${ }^{25}$

La Monte Young's piece Composition 1960 \#5, mentioned in the previous chapter, adopts this sound-as-idea approach in that the flapping wings of butterflies visually suggest a sound universe that one has to imagine. The sounds made by the butterfly wings are inaudible to the human ear. In Composition 1960 \#5 we can say that the

\footnotetext{
${ }^{24}$ LaBelle, Brandon. Background Noise: Perspectives on Sound Art (New York: Continuum, 2006) p. 60

${ }^{25}$ Khan (2001) p. 277
} 
idea of sound is present (even heightened) through its absence. Young offers his own account on the inaudibility of sound concerning Composition 1960 \#5:

...it didn't seem to me at all necessary that anyone or anything should have to hear sounds and that it is enough that they exist for themselves. ${ }^{26}$

The following quote by Fluxus artist Yoko Ono further exemplifies a prevalent attitude within the gallery arts during the 1960s in which sound was valued for its conceptual properties:

I think of my music more as a practice than a music. The only sound that exists to me is the sound of the mind. My works are only to induce music of the mind in people. ${ }^{27}$

Understood from a conceptual point of view, the audible detail of sound is not important, but rather it is the idea of sound that is important. Fluxus performances edged the art world closer to an extramusical appreciation of sound by challenging the conventional premise that sound must be heard to be relevant.

This conceptual idea of sound, which surfaced during the early 1960s was made possible by the neo avant-garde acceptance of the expanded field, an expanded field that was not only material but also conceptual. The willingness of Fluxus performance artists to embrace the expansive multifarious field of experience as explored by Cage in 4'33" freed up artists to expand their art into previously unexplored material and conceptual realms.

\footnotetext{
${ }^{26}$ Joseph (2008) p. 94

${ }^{27}$ Khan (2001) p. 240
} 
Aside from the performance-focused activities of the Fluxus artists, the visual arts, including sculpture, had an equally important role to play in claiming the idea of sound as a valid artistic preoccupation. Seth Kim-Cohen's writing champions the role of the visual arts in establishing the sound-as-idea concept, or what KimCohen refers to as 'non-cochlear' sonic art. In his publication In the Blink of an Ear (2009) Kim-Cohen points to the multimedia artwork Box with the Sound of Its Own Making (1961) by the sculptor Robert Morris as an example of a work that illustrates the conceptual shift from an examination of the acoustical properties of sound toward the use of sound that takes into account the 'expanded situation' (a phrase which can be deemed interchangeable with the expanded field concept). Morris' Box consists of a wooden box, within which an audio recording is played. The subject of the audio is a three-hour recording of the box under construction. Kim-Cohen describes the multidimensional allure of Morris' Box as:

... simultaneously the product of a process, the documentation of that process, and a set of instructions for the replication of that process...In Box the "score" for the sound material of the work is only available (constructable) [sic] after the performance/production of the box... ${ }^{28}$

Kim-Cohen makes the observation that the acoustical properties of sound are not important in this context, 'sound is not included exclusively, or even primarily, for its auditory-aesthetic qualities. ${ }^{29}$ It is the subject of the recording and the temporal displacement that the subject of the recording conveys that is most relevant.

\footnotetext{
${ }^{28}$ Kim-Cohen, Seth. In the Blink of an Ear: Toward a Non-Cochlear Sonic Art (New York: Continuum, 2009) p. 49

${ }^{29}$ ibid p. 51
} 
Morris utilizes the sound recording to suggest an expanded situation synonymous with the concept of an expanded field. The viewer encounters a sculpture, the audio content of which suggests not only another time, but also another space, that other space being the location in which the box was constructed. The expansion is, of course, more than physical, but conceptual as well. The expansive situation implies spatial multiplicity: conceptual space as revealed by the subject of the audio, and material space in terms of the viewer's physical encounter with the box in its place of residence. The holistic perception that the viewer gleans from the artwork is determined by the multitude of elements that are in spatial play.

Morris' Box is a fine example of an artwork that articulates the multifarious field of relations that make up an expanded field. As such it can be taken as representative of the sound-as-art principle. Box is not musical; it is noisy. It hints at corporeality by way of human presence referred to in the audio content. In other words, conceptually, it could be conceived of as a performance (albeit a recording of a performance). It is an artwork where (like $\left.4^{\prime} 33^{\prime \prime}\right)$, noise, corporeality, and the expanded field, converge.

Perhaps the most striking observation made by Kim-Cohen, in his assessment of the sound-as-idea premise, is his comment concerning Alvin Lucier's sound recording, I Am Sitting in a Room (1969). This piece consists of a recording of the artist repeatedly replaying a recording of his own voice into a room so that the resonant character of the room transforms his words over time into a reverberant mumble. Kim-Cohen says of Lucier's piece, ‘...in order to best engage [with] it, 
one need not, perhaps even should not, listen to I Am Sitting in a Room. ${ }^{30}$ This is an illustration of how far sound in the arts had come by the end of the 1960s: from the corporeally inclusive, (self-proclaimed) musicality of Cage, to the non-musical sonic explorations of Young and Fluxus, to the primarily conceptual sound-as-idea experiments emerging from artists such as Morris and Lucier. The 1950s and 1960s had transformed the artistic treatment of sound from a strictly musical material into an extramusical material operating within the context of an expanded field that was conceptual as much as it was physical.

So far this thesis has concentrated on tracing the rise of noise, corporeality, and the expanded field in establishing an extramusical appreciation for sound in the arts. The next chapter introduces a sound-based practice at odds with the corporeally inclusive sound-as-art aesthetic. During the 1950s, whilst Cage was experimenting with theatre and an expansive sonorous field, the development of electronic sound recording studios offered an altogether different approach to the creation of soundbased work. The next chapter will turn to the work of the French radio engineer Pierre Schaeffer in setting up a contrast between the corporeally inclusive sound art of Cage and the non-corporeally-based sonic art of Schaeffer.

${ }^{30}$ Kim-Cohen (2009) p. 193 


\section{CHAPTER 5}

\section{Non-Corporeal Sonic Art versus Corporeal Sound Art}

The rise of electroacoustic music studios during the 1950s and 1960s brought about a culture of the acousmatic, which in many respects is different to the corporeally inclusive sound art embraced by the likes of John Cage, Fluxus artists, and the sculptor Robert Morris. This chapter will introduce the acousmatic approach, and articulate the distinctions between non-corporeal acousmatic composition and the corporeally inclusive sound-as-art.

The idea of the acousmatic in electroacoustic music nurtured a very specific approach to the art of listening and music making. Beginning with the creation of musique concrète in 1948 by French radio engineer Pierre Schaeffer, an ideology of the acousmatic begins to take root for those involved in the conception and creation of studio-based works. Schaeffer describes the acousmatic as 'referring to a sound that one hears without seeing the causes behind it'. ${ }^{31}$ Made possible by the then new recording technology of magnetic tape, sections of recorded sound could be isolated and subjected to studio manipulation. Schaeffer would come to refer to the isolated sound event as l'objet sonore or sound object. Schaeffer insisted on the abstraction of the sound object via a method of phenomenal reduction, which he termed reduced listening. Reduced listening is a listening approach that requires the listener to suspend external real-world references to the sounds they hear. As

\footnotetext{
${ }^{31}$ Schaeffer, Pierre. Traitë des objets musicaux (Paris: editions du Seuil, 1966) p. 91
} 
Brian Kane succinctly states, the role of acousmatic listening is the nullification of, 'visible, tactile and physically quantifiable assessments' of sound. ${ }^{32}$ Any visual or physical reference is seen as a contaminant to the acousmatic goal of perceiving the sound object, in abstraction from its real-world origin or meaning. The notion of the corporeal was, and in some respects still is, anathema to acousmatic music, and its elimination of physical reference establishes the acousmatic as the antithesis of the corporeally inclusive.

In my opinion, two sound-based traditions emerged out of the 1950s and 1960s when the acousmatic provided a new approach to the creation of sound-based work: One of those traditions is what I will term Non-Corporeal Sonic Art whose lineage primarily stems from studio-based activity involving the acousmatic and a fusion of the technological within a musical compositional framework. The second is what I will term Corporeal Sound Art; a tradition whose conceptual and interdisciplinary scope was forged by artists grounded in the philosophy of art and does not necessarily involve a musical framework.

Corporeal sound art can be seen as a continuation of the foregrounding of the artist's body and the extramusical, introduced by the early twentieth-century avantgarde. Aside from sound-based artists who use sound in extramusical ways, body artists and performance artists who employ sound as part of their multi-disciplinary praxis are considered part of this lineage. Alternatively, the non-corporeal sonic art tradition has served to marginalize the body in order to highlight either the sound

\footnotetext{
${ }^{32}$ Kane, Brian. 'L'Objet Sonore Maintenant: Pierre Schaeffer, sound objects and the phenomenological reduction' Organised Sound: An International Journal of Music Technology (Vol 12 (1) 2007, pp. 15-24)
} 
object in acousmatic recordings or the mechanical and computational complexity of technology. In non-corporeal sonic art the body of the musician or software programmer is seen as a neutral mediator whose role is to articulate music via external instrumentation. Activities such as laptop performance fall within this category. Alternatively, in corporeal sound art the body is seen more as an organism capable of dynamic and varied sonification in and of itself.

What follows is a summary of what I deem to be the main features that distinguish corporeal sound art from non-corporeal sonic art:

\section{Corporeal Sound Art}

- Human corporeality dominates technology.

- External processing: highlights the physical environment inclusive of human corporeality.

- Extramusical framework: accepts all sound as art material, as pertaining to the sound-as-art trivium.

\section{Non-Corporeal Sonic Art}

- Technology dominates human corporeality.

- Internal processing: highlights technology, virtual (electronic and/or digital) as opposed to the physical.

- Musical framework: acousmatic music continues the classical tradition of treating sound as an abstract ideal, as sound-in-itself. Sound is viewed as an autonomous object. 
When I speak of external processing, I am referring to the transformative effect of aural architecture on sound waves that are projected into a physical space, such as a concert hall or gallery interior. These physical environmental factors play a prominent role in the conception and outcome of the sound work. Pendulum Music (1969) by Steve Reich (performance), Dreamhouse by La Monte Young (installation), and Alvin Lucier's I Am Sitting in a Room (recording) are all examples where intentional external processing is employed. In contrast, when I speak of internal processing I am referring to electronic and/or digital processing done inside a device such as the central processing unit of a computer. Any performance that employs a MaxMSP patch for example, adheres to this form of processing. The processing is virtual and does not rely on the physical world (macro-scale) for processing determination. External processing is subject to a swath of environmental factors such as temperature fluctuation, electromagnetic interference, and the acoustically absorbent properties of building materials and audience bodies. External processing must take into account the expanded field as an ecosystem, which includes multiple entities. This kind of ecological situation, which requires the performer to relinquish control to other entities/objects, is quite opposed to the total control possible in the studio.

The corporeal sound art and non-corporeal sonic art categories are not strictly independent and it is only natural that corporeal and non-corporeal qualities intersect in the practical application of sound-based creative work. This is particularly evident in contemporary performance works where virtual systems are commonplace. ${ }^{33}$ Nevertheless these two categories are quite useful for describing

${ }^{33}$ This will be discussed at length in Chapter 8 
sound-based activities from the 1950s until approximately the mid-1990s when there seemed to be two separate ideologies in play; one favoring technological foregrounding at the expense of the body, and the other accepting of technology as a complement to body-centred performance practices.

Regarding non-corporeal sonic art, I would like to note that studio-based activity has, over time, expanded our compositional outlook to focus on concepts that have traditionally been at the forefront of the corporeal arts, such as the idea of space and field as structural parameters. Concepts such as spatiomorphology and spectromorphology as defined by Denis Smalley within the realm of electroacoustic composition, has shifted attention away from the traditional classical parameters of time, harmony and melody. ${ }^{34}$ However, despite the exploration of non-classical musical parameters in studio-based composition, the compositional framework deriving from the non-corporeal acousmatic lineage remains a musical one.

Trevor Wishart alludes to the musical nature of electrocaoustic composition in his seminal publication On Sonic Art. According to Wishart, notated music adheres to a lattice arrangement, and electronic music has expanded the lattice construct by approaching sound as a continuum rather than as a series of discrete units (notes and time values for instance). Wishart suggests we rid ourselves of the restrictive nature of classical notation, "we do not need to deal with a finite set of possibilities. ${ }^{35}$ At the very least Wishart proposes that, 'sound-art can no longer be

\footnotetext{
${ }^{34}$ Smalley, Denis. 'Spectromorphology: explaining sound shapes' Organised Sound: An international Journal of Music Technology (Vol. 2 (2) 1997, pp. 107-126)

${ }^{35}$ Wishart, Trevor On Sonic Art (Amsterdam: Harwood Academic Publishers, 1996) p. 7
} 
confined to the organization of notes. ${ }^{36}$ However, Wishart maintains his connection to music by concluding at the end of his introduction, '...this book assumes that there is no such thing as an unmusical sound-object. ${ }^{37}$ This is very reminiscent of Cage's premise that all sounds can be considered music. Again this does not represent a clean break from musical structure. Electroacoustic composition includes all sounds in the formation of a studio-based musical practice.

In my reading, Wishart's description of the electroacoustic continuum is merely one step removed from traditional musicality, whereas post-World War II neoavant-garde sound experimentation (as evidenced in the work of Kaprow, Fluxus and Morris for example) turns its back on music completely with its goal of employing the sonic in collaboration with other materials in the pursuit of soundas-art.

Due in part to a growing appreciation for the acousmatic throughout the 1950s and 1960 s, the body became increasingly marginalized for sound-based composers whose creative output stemmed from the recording studio environment. Alternatively, sound-as-art and corporeal inclusiveness continued to find favour within the general art world. The next chapter will examine extramusical experimentation by live electronic protagonists using real-time external processing. The rise of body-centred art practices will also be discussed and a philosophical

\footnotetext{
36 ibid p. 7

${ }^{37}$ ibid p. 8
} 
argument presented to champion corporeality in light of the popularity of the acousmatic. 


\section{CHAPTER 6}

\section{Real-time External Processing and the Emergence of the Performance Art Genre}

Aside from the activity being carried out by acousmatic composers during the 1950s and 1960s, a further area of research pursued by sound-based artists was that of real-time processing of electronically generated noise in performance contexts. The period also gave rise to several body-centred art movements such as the Gutai Group (Japan) and the Viennese Actionists. While the Viennese Actionists and Gutai Group were not concerned with sonic exploration, they expanded modernist notions of corporeality by treating the physical body itself as a primary subject for their art. This chapter will examine these body-centred art movements and comment on the corporeal philosophy of Maurice Merleau-Ponty. But first I will make mention of the real-time exploration of electronic sound by alluding to the work of sound-based performance collectives such as the Sonic Arts Union and the Theatre of Eternal Music.

Organizations such as the Sonic Arts Union and the Theatre of Eternal Music (also known as The Dream Syndicate), both formed during the 1960s, were involved in the real-time creation of sound-based works outside the confines of the recording studio. Such activity by these experimental collectives was in marked contrast to the acousmatic practices of electroacoustic studio composers. Public exposure to studio-based compositions was restricted to the acousmatic and non-performative media of radio broadcast and acousmatic tape music concerts. By contrast, the 
Sonic Arts Union and the Theatre of Eternal Music chose to conduct their real-time electronic experimentations in front of public audiences. Although the interests of their members were diverse, through their predilection for live performance, external processing was a constant consideration for these groups. This was especially true for the Theatre of Eternal Music (featuring La Monte Young and Tony Conrad) for whom discordant feedback and sustained sound formed a large part of their experimentation.

During the 1960s numerous sound artists adopted extreme volume and sustained sound as a stock strategy. Such an approach exposed the spectator to the physical force of sound waves. This phenomenon was exploited by John Cage for Variations VII, performed at the $69^{\text {th }}$ Regiment Armory in New York in 1966 as part of 9 Evenings: Theatre and Engineering. For this performance electronic sounds were modulated and affected throughout a large reverberant space. In such performances, the audience's experience of sound is immersive, all-encompassing, and physical. Perception of this kind of sound performance is not an intellectual exercise. Instead, one feels such events, for sound at high amplitude is not only registered by the ears, but resonates throughout the whole body (with different frequencies creating resonances in different areas of the body), creating a holistic corporeal reading of the sound event. ${ }^{38}$

Working with this kind of performance approach, one concerned with the morphology of sound waves in relation to architectural interiors, the sound artist is

\footnotetext{
${ }^{38}$ The concept of 'corporeal listening' (listening with the entirety of the body) is central to the work of sound sculptor Bernhard Leitner who has written extensively on the subject.

- http://www.archdaily.com/168979/bernhard-leitner-sound-spaces/
} 
regarded more as a sculptor of sound rather than as a composer in the conventional sense. The creators of such works enter into a reflexive relationship with the environment, bringing forth an ecological awareness of the expanded field for both practitioner and spectator. ${ }^{39}$ Such an approach also includes, necessarily, a highlighting of (often mundane) objects via sonic amplification. David Tudor's Rainforest Series (1968-1973) in which contact microphones are attached to everyday materials to be amplified, epitomizes this focus toward objects that we traditionally have not regarded as instruments or as playing a role in musical composition.

The understanding that the reception of sound is a corporeal act (i.e. sound is registered by the totality of the body) coupled with an increased willingness to amplify non-traditional objects, opens up the prospect of viewing the physical human body itself as a source for sonorous material (beyond the voice). Alvin Lucier's composition Music for Solo Performer (1965) exemplifies this progression toward viewing the human body as a site for live sound experimentation. In this piece, electromyography electrodes are attached to the scalp of the performer. The alpha waves generated by the performer's brain produce electrical signals that trigger the behavior of percussion instruments located throughout the performance space. ${ }^{40}$

\footnotetext{
${ }^{39}$ This practice of having a working relationship with the expanded field is very much alive today in the work of sound artists such as Malcolm Riddoch - http://malcolmriddoch.com/

40 The sonorous body as a subject and object for electronic performance would gain traction during the 1980s and 1990s, when several artists of the period fused the digital technology of the times (software and hardware) with the corporeal, exploiting full-body gesture in the production of manmachine hybrid instruments. This will be discussed in the following chapter.
} 
Concurrent to these activities in the 1950s and 1960s, and as a complement to the real-time experimental sound work of electronic performance artists, were the corporeal investigations of various performance collectives including the Gutai Group and the Viennese Actionists. The pioneering work by these groups would bleed into the 1970s, prefiguring a proliferation of specialist body artists.

The Gutai Group, formed in Japan in 1954 by Jiro Yoshihara and Shozo Shimamoto, was an art movement with a corporeal focus. The Japanese word Gutai literally means 'embodiment'. The Gutai group was interested in using the human body in combination with other materials in the pursuit of revealing the inner life of inanimate objects. The real-time deconstruction of inanimate materials was seen as a process of beautification. The corporeal was central to the Gutai aesthetic and the human body in its entirety was often integral to the creation of Gutai artwork. $^{41}$

The Viennese Actionists were active in Austria throughout the 1960s and included artists such as Günter Brus, Otto Mühl, and Hermann Nitsch. The Viennese Actionists often performed naked and were known for submitting themselves to violent acts of self-harm. The naked body served to nullify cultural signifiers by way of exposing the audience to a common animalistic humanity devoid of class status and nationality. They challenged society's moral codes by performing provocative acts involving body fluids and sexual taboos. Writer and performance practitioner Susan Broadhurst describes Viennese Actionism as signifying:

${ }^{41}$ Two examples of such works are Laceration of Paper (1955) by Murakami Saburo in which the artist hurls himself through forty sheets of paper, and Challenge to Mud (1955) by Kazuo Shiraga (1955) in which the artist writhes in a pool of mud. 
....a longing for the primordial nature of the creative...concerned not only with destroying structures and languages, but also with the expressive cathartic act that goes beyond language. ${ }^{42}$

The birth of these performance art movements in Austria and Japan illustrate the cross-cultural (Eastern and Western) attraction to the corporeal. The formation of these groups in isolation is testament to the universal appeal of the physical human body, providing the vehicle through which non-linguistic modes of communication can be explored, and traditional language and culture questioned. ${ }^{43}$

The idea of using the body as a means to bypass cultural norms resonates strongly with the philosophy of existential phenomenology. This body-centred strain of phenomenology, introduced in the late 1940s by the writer Maurice MerleauPonty, argues for corporeality as to our perception of the world. ${ }^{44}$ This view is in marked contrast to transcendental philosophy, such as that of Edmund Husserl (whose work informed Pierre Schaeffer's de-corporealized theories of sound), which was predominant in the mid-twentieth century. Transcendental philosophy takes the position that the human mind and consciousness are separate areas of study from the corporeal. By contrast, for Merleau-Ponty the mind and body are intertwined. Human perception works on a centralizing organizing principle emanating from the sense organs. Merleau-Ponty was interested in the primacy of perception and claimed that when seen from a corporeal point of view, we experience our world in the round. Merleau-Ponty's work was pioneering in this

\footnotetext{
${ }^{42}$ Broadhurst, Susan. Liminal Acts: A Critical Overview of Contemporary Performance and Theory (London: Cassell, 1999) p. 100

${ }^{43}$ This ability of the body to question language and culture will be further alluded to in Chapter 8 when discussing the value of both the corporeal and noise as tools in the exploration of liminal activity.

${ }^{44}$ Merleau-Ponty, Maurice Phenomenology of Perception (trans.) Colin Smith (London: Routledge and Kagan Paul, 1962)
} 
respect, anticipating recent developments in the sciences such as the field of embodied cognition, which offers a perspective very similar to that of MerleauPonty's phenomenology:

The human mind-brain is an organically embodied representational system, a system that enters into states that are systematically interrelated and that stand in intentional relations to the environment in which the human organism is embedded (Nussbaum in Ferrar) ${ }^{45}$

My existence as subjectivity [i.e. consciousness] is merely one with my existence as a body and with the existence of the world, and because the subject that I am, when taken concretely, is inseparable from this body and this world (Merleau-Ponty) ${ }^{46}$

Not only does Merleau-Ponty's philosophy prioritize the centralization of the corporeal but he also claims that our relationship to the environment is a reciprocal one and that we are inseparable from our surroundings. Both body and environment are implied in each other. We, as material thinking bodies, perceive in relation to other bodies within a field of relations. This idea resonates with the notion of the expanded field. In Merleau-Ponty's phenomenology we find a strong philosophical underpinning of two of the three principles that make up the soundas-art trivium: corporeal foregrounding and the notion of an expanded field consisting of multifarious relations. Indeed, throughout the 1960s and leading into the 1970s and beyond, Merleau-Ponty's philosophy offers support for the continuing relevance of body-based art forms. However, it was not until the 1970s that terms such as performance art and body art began to surface as part of curatorial jargon. During the 1970s (in large part, due to the pioneering work of the Viennese Actionist's and Gutai), specialist body artists such as Vito Acconci, Chris

\footnotetext{
${ }^{45}$ Ferrer, Rafael, 'Embodied Cognition Applied to Timbre and Musical Appreciation: Theoretical Foundation'. http://www.bpmonline.org.uk/bpm10/ferrer_rafaelembodied_cognition_applied_to_timbre_and_musical_appreciation_theoretical_foundation.pdf ${ }^{46}$ Merleau-Ponty (1962) p. 8
} 
Burden, Tehching Hsieh, and Marina Abramovic sought to test the physical limitations of the body, often submitting the body to extreme conditions in performance situations.

Marina Abramovic is an example of a performance artist whose oeuvre adheres to the corporeal sound art aesthetic. Although it would be a stretch to label Abramovic a sound artist per se, when she has employed sound as part of her performance practice, she has used technology sparingly in order not to distract from the experiential crux of her work whose strength is derived from the psychological pull of corporeal presence. In her performance Rest Energy (1980), performed in collaboration with the artist Ulay (Frank Uwe Laysiepen), each artist stands to face each the other. The string of a bow is held taut by Ulay. An arrow is placed in the bow and aimed at the heart of Abramovic. Small microphones rest on the chests of each performer to detect the sound of their hearts beating. The amplification of the audible heartbeat is intended to draw attention to the anxiety and tension felt by both performers as Ulay struggles during the performance to keep the bow in the firing position. Technology in this instance is incorporated in order to amplify and intensify corporeal presence. In this sense, Rest Energy is indicative of a corporeal sound art approach. Moreover, it relates to much of the performance art that preceded it in the 1960s and 1970s in that technology was seen as complementary to corporeal and environmental factors, rather than as a means for artistic production in its own right.

In the real-time sonic experimentation carried out by the likes of the Sonic Arts Union, and body-based performance art carried out by artists like Abramovic; 
corporeality, environment, and technology are each valued to the degree in which they add to the effectiveness of the total artwork. Such corporeally grounded investigations into the expanded field (of which technology plays but a part) would be superseded in the 1980s by a radically different approach to performance.

Digital media in particular would present a challenge to corporeal relevance with the non-corporeal sonic art approach discussed in Chapter 5 resurfacing in a new guise. Unlike the acousmatic activities of the 1950s, at this juncture in history, the non-corporeal would not be confined to the electroacoustic studio but would be presented as a performance activity. 


\section{CHAPTER 7}

\section{The Age of Digital Enhancement}

During the 1980s digital technology played a vital role in altering our perception of the performing body. With the arrival of the MIDI protocol and the advent of the personal computer, real-time investigation of sound in the material world (practiced in the 1960s and 1970s) shifted to an investigation of sound through the computation of data in digital software. This initial incorporation of digital media into the general art world sidelined the body to some extent. The value of the corporeal in this working environment was gauged by the degree, to which it could be used to help illustrate practical uses for software design; that is, the body became a prosthetic extension of 'the user'. This was a dramatic role reversal for the body, which over the course of three decades (1950s to1970s), had been given a strong role within the gallery arts.

Emerging in 1983 the MIDI protocol enabled composers and performers to manipulate control parameters in real-time. The real-time applications of this new technology enabled studio-based composers to transplant their studio environment onto the performing stage. Consequent advances in software design and continual improvements in the processing power of computers throughout the 1980s and 1990s further emboldened composers and sound engineers to foreground the musical potential of technology in performance contexts. The advent of laptop performance is a clear example of this kind of practice, and highlights the displacement of the corporeal and continuation of the non-corporeal approach of 
electrocaoustic music in technologically focused work. As Kim Cascone, an important early proponent of laptop performance explains:

The laptop musician broadcasts sounds from a virtual non-place; the performance feigns the effect of presence and authenticity where none really exists. The cultural artifact produced by the laptop musician is then misread as "counterfeit", leaving the audience unable to attach value to the experience. The laptop performer, perhaps unknowingly, has appropriated the practice of acousmatic music and transplanted its issues. ${ }^{47}$

To my mind, the 1980s represents a revival of the non-corporeal sonic art approach. As with the advent of the electroacoustic music studio in the 1950s, technology and sound-in-itself became the focus. Furthermore, not only was corporeality sidelined but attention shifted from external processing to internal processing. Digital sound processing and sound generation established a focus on 'black box' creativity. This was in contrast to the work of Sonic Arts Union artists, and others, who explored the interface between technology and the physical world, including the body.

Despite this re-invigoration of the non-corporeal there were also a number of artists in the 1980s that sought to investigate how the corporeal could be integrated into the digital processing environment. Not surprisingly, advocates of this kind of research emerged from the field of performance art. Stelarc was one such performance artist who saw digital technology as a positive addition to his corporeally-based research.

\footnotetext{
${ }^{47}$ Cascone, Kim. Comatonse Recordings: Articles \& Reviews. Computer Music Journal (Vol 24 (4) 2000, pp. 91-94)
} 
Stelarc is an interesting case study as his oeuvre conveniently reflects the changing face of performance art, moving from the 1970s into the 1980s and beyond. Stelarc's early work during the 1970s was concerned with body deprivation. Akin to Marina Abramovic and many performance artists of that time he was interested in testing the limits of what his physical body could endure. For example, during the 1970s, he performed a series of suspension pieces in which he suspended his naked body in mid air, supported by metal hooks pierced into his skin. These pieces utilized material technologies (such as metal hooks and lengths of rope). By contrast, in Stelarc's work of the late 1980s and 1990s we find an artist who has immersed himself in digital technology. Some of Stelarc's projects, such as Third Hand (1990) and Robotic Arm (1992) explored the use of prosthetics. Such prosthetic devices served to amplify and augment the body's nervous system, expanding the body's field of influence. In Stelarc's Movatar/Avatar performance (1997) an inverse motion-capture system was employed. A motion prosthesis interface was wrapped around the performer's upper torso, the arms of which were controlled by a computer entity whilst the performer's legs affected various elements of the computers behaviour. Hence, a dialogue ensued between performer and artificial entity. The computer programme projected its abstract body presence on the wearer of the Movatar prosthetic. Using an inverse connectivity, (the machine controlling the human rather than the standard vice versa situation) the performance underscored the potential of artificial entities to affect physical actualizations on a human body.

According to Stelarc, over the last twenty-five years the 'obsolescence of the human body' has been the primary theme that has permeated his performance 
work. $^{48}$ In my opnion however, and despite Stelarc's avowed intention, from an audience perspective the body has been the subject and focus of his performances (albeit a technological body), in the sense that the body takes on the role of controller or the controlled to varying degrees. According to the author Amelia Jones:

Stelarc's performance practice is powerful because it labours to concretise and deabstract [sic] the effects of new technologies by enacting them through the body. ${ }^{49}$

When seen in this light, Stelarc's cyborg innovations, hybrids of machine and human, can be viewed as foregrounding the corporeal through technological means, which places his work in marked contrast to laptop performance.

Although sound has been known to play a role in Stelarc's performances (for example in Third Hand the artist incorporated sensors attached to prosthetic joints to detect and trigger sound events) there are clearer examples of artists who have combined the corporeal and technology in the pursuit of sound-based outcomes. Laetitia Sonami is an example of a performance artist whose synthesis of technology and body is focused on sound.

Sonami is best known for her performances involving the 'Lady's Glove', a wearable lycra glove which has been augmented with numerous sensor technologies including contact switches, bend sensors, and accelerometers. ${ }^{50}$ 'Lady's Glove' has been an ongoing project for Sonami. First performed with in 1991, her wearable instrument has undergone many modifications. Sonami

\footnotetext{
${ }^{48}$ Stelarc, Obsolete Body, Stelarc homepage. http://www.stelarc.va.com.au/obsolete/obsolete.html 49 Jones Amelia, STELARC, The Monograph, Marquard Smith. (ed.) (Massachusetts: MIT Press, 2005) p. 97

${ }^{50} \mathrm{http}: / /$ www.sonami.net/works/ladys-glove/
} 
collaborated with several software/hardware designers throughout the 1990s in an effort to improve the performative apsect of her instrument. Collaborators have included Paul DeMarinis for the original glove in 1991 and Bert Bongers in 1994. This collaborative approach involving software/hardware designers working with performers during development, often results in productive outcomes in the sense that equal attention can be given to sound design as well as expressivity of gesture on the part of the performer.

Sonami's performances involve the intricate movement of fingers and hand gesticulations that trigger sounds and alter signal parameters. She combines these sounds with spoken text, video imagery and dramatic lighting. Sonami's performances are engaging for two reasons: Firstly because the software, hardware and performance methodology have been prepared as parts of a shared system. Hence, the connection between performance gestures and the digitally processed sounds are explicitly interwoven so that the audience can easily register a correlation between gesture and sonic result. Secondly, Sonami brings into play the expanded field of her performance environment. As opposed to a laptop performance where the technology is foregrounded at the expense of corporeal and environmental concerns, Sonami succeeds in embracing the expanded field by utilizing a multitude of elements in the pursuit of an overall holistic dramaturgy that is typical of intermedia art. $^{51}$

\footnotetext{
${ }^{51}$ Sonami and Stelarc were part of a wider group of sound-based performers during the 1990s that utilized wearable technologies as a way to investigate how the corporeal could be combined with technology. Michael Waisvisz; creator of 'The Hands' (a gesture-based controller), and Atau Tanaka (who employed muscle sensors in full-body kinetic performances) are two further examples to add to the works of Sonami and Stelarc.
} 
Incorporating technology which involves hardware as much as it does software, Stelarc and Sonami require the corporeal as much as the technological. Such research represents a combination of both corporeal and non-corporeal qualities. Regarding the performance examples just discussed — to the technology—one can just as easily state that it is via the corporeal that these technologies come to life.

Aside from aiding in the proliferation of hybrid machine bodies, digital technology in the form of virtual systems technologies has also provided us with novel contexts in which to present performance work. Over the past several decades numerous scholars have sought to challenge the historical view that live performance is a corporeal activity. For example Phillip Auslander has written extensively about how the traditional role of the corporeal as holding a central position in live performance no longer applies. Auslander challenges what he regards as:

...the common assumption...that the live event is 'real', and that mediatized events are secondary and somehow artificial reproductions of the real. ${ }^{52}$

Auslander rightly states that many contemporary performances are mediatized. $\mathrm{He}$ is referring to performances that project imagery in the absence of physical bodies, but he could just as easily be referring to the projection of sound in the absence, or at least the marginal presence, of a physical performer (i.e. acousmatic sound diffusion). Mediatization is a term borrowed from Jean Baudrillard to describe the compression of all discourses into a single stream. ${ }^{53}$ As the contemporary cliché

\footnotetext{
${ }^{52}$ Auslander, Philip. Liveness: Performance in a Mediatized Culture (New York: Routledge, 1999) p. 3

${ }^{53}$ Baudrillard, Jean Simulacra and Simulation (trans.) Sheila Faria Glaser (Ann Arbor: University of Michigan Press, c1994)
} 
has it, 'it's all just data'. For Auslander this definition of mediatization is apt to describe the oneness of technological mediation and the real in terms of live perception.

According to Auslander the projection of a human face on a video screen is just as real as being in the presence of a physical face. For Auslander the physical presence of the actor is no longer necessary for a contemporary audience to register live presence. Indeed, our contemporary society has become conditioned to accepting digital images as reality, as is evident in many performances by contemporary popular music artists, in which the distinction between live and mediatized elements is often tenuous at best (an example would be Beyoncé's hyper-multiplication of herself in her 2011 Billboard Award performance) ${ }^{54}$

What is interesting about the way Auslander describes the mediated context in which contemporary society finds itself, is the idea that our sense of connectivity to the physical world is intertwined with the virtual worlds of television, radio and the Internet, among other media. Our virtual connectivity radically extends the expanded field to include our mediatized environment inclusive of virtual reality, which according to Auslander is no different than physical reality. Contemporary performance works become less about corporeality and the physical environment to being about the body as part of (plugged into) a wider world, which is becoming more connected through digitization.

\footnotetext{
${ }^{54} \mathrm{http}: / /$ www.youtube.com/watch?v=NPP10z9nz81\&feature $=$ fvsr
} 
I began this chapter by claiming that the 1980 s represented a revival of the noncorporeal sonic art approach. I would like to conclude the chapter by suggesting that the potential of digital technology to disembody the corporeal from our perception of reality is ultimately one of personal choice. Users of digital technology can choose to foreground the technology itself, or one can take the corporeal sound art standpoint and apply digital technology as a complement to corporeal concerns. I hold up Stelarc and Sonami as examples of the latter, while laptop performance is more in line with Auslander's ideas concerning the perceived reality of mediatized performance. The next chapter will discuss the continued relevance of the body as a part of our mediatized world and reveal the body's ongoing potential to address contemporary themes despite digital technology's influence on our perception of the live. 


\section{CHAPTER 8}

\section{Corporeal Relevance in the Age of Digital Mediatization}

Despite the digitally mediated context in which contemporary art finds itself, this chapter will argue for the corporeal as a timeless site for addressing issues central to the human experience. Although we possess an unyielding curiosity to embrace technology, paradoxically we also crave the familiarity of the corporeal when technology dominates. This contradictory nature of man's relationship with technology will be touched on at various points in this chapter. Furthermore, I will assert that the material human body is the mediating constant in the face of digital technology. I will conclude by claiming that a synthesis of body, noise and digital technology offer a potent means through which liminal activity can be highlighted and explored.

Throughout the course of human history numerous examples abound concerning mankind's affection for the human body as an organizing principle. Examples include the abstract symbolism to be found in Paleolithic figurative sculpture ${ }^{55}$ the Classical orders of architecture as described by the ancient Roman architect Vitruvius, ${ }^{56}$ and the human body featured in European medieval manuscripts in

\footnotetext{
${ }^{55}$ For example the Venus of Willendorf dated 24,000-22,000 BC. Similar figurines have been found throughout Europe suggesting this recurring figure is a metaphorical representation of the earth mother.

${ }^{56}$ See Vitruvius Book III of his treatise De Architectura in which he credits the human figure as providing the proportions for the Classical Orders of Architecture. Vitruvius, Pollio. De Architectura (trans.) Richard Schofield (London: New York: Penguin, 2009)
} 
which the trinity of Christian soul, God and King are represented in microcosm. ${ }^{57}$ According to anthropologist Jonathan Benthall, 'the body is perhaps the foremost of all metaphors for society's perception of itself, recurring constantly in myths and cosmologies, art and literature. ${ }^{58}$

A point to add to this realization that the metaphorical human body looms large over the course of human history, is that one's individual interpretation of the metaphorical body is dependent on cultural factors. For example the human body in Indian tantric yoga is to be viewed holistically, as an all-encompassing, selfcontained unit, whereas the medieval Christian body is ambiguous, and in Benthall's words, fluctuates 'between glorification and mortification'. ${ }^{59}$ So it follows that how we understand the physical body in the twenty-first century is relative to our present-day global cultural condition, a condition largely defined by the complex communication infrastructure that digitally mediates our lives. In such an environment, our interaction with non-corporeal bodies is commonplace, such as when we communicate via videophone or telephone.

Adding to the realization that our environment has conditioned us to accept noncorporeal, non-physical beings and events, the author Robert D. Romanyshyn has another interesting take on the ease with which contemporary society entertains the non-corporeal. In Technology as Symptom and Dream (1989) Romanyshyn alludes to the idea that contemporary humankind instinctively craves departure from the

\footnotetext{
${ }^{57}$ Sawday, Jonathan. The Body Emblazoned: Dissection and the Human Body in Renaissance Culture (London: Routledge,1995)

${ }^{58}$ Benthall, Jonathan and Ted Polhemus (eds). The Body as a Medium of Expression (London: Penguin Books Ltd, 1975) p. 10

59 ibid p. 10
} 
corporeal. ${ }^{60}$ According to Romanyshyn humans possess an inherent desire to transform their terrestrial bodies into extra-terrestrial ones, as a technologized analogue of the religious desire for a release from the physical through the spiritual. Writing at the end of the 1980 s, the author refers to post-1950s space exploration, and specifically the technologically enhanced astronaut as emblematic of our desire to transform the earth-bound body (or what Romanyshyn refers to as 'archaic man') into an extra-terrestrial body. As Romanyshyn explains:

The conjunction of space man's appearance and archaic man's disappearance is...nothing more than a harbinger of our wish to take leave of a flesh so fragile and so frail, flesh which is always finally heir to death. ${ }^{61}$

According to Romanyshyn, Western curiosity regarding technological body modification can be attributed to more than just an aspiration for an improved body or a more efficient body (as seems to be the case in Stelarc's work). The idea that mankind can cheat death is also a part of this fascination we hold for a technologically enhanced body. Ultimately, Romanyshyn goes on to suggest that this extra-terrestrial body is unattainable for 'in order to escape death our departure from earth would have to be total and complete. ${ }^{, 62}$

Romanyshyn also raises the point that mankind's journey into extra-terrestrial space has opened us up to the possibility of viewing our material world from a distance. Interestingly, Romanyshyn puts forward the idea that it is through our bodily separation from the earth that we crave for a return to terrestrial familiarity:

\footnotetext{
${ }^{60}$ Romanyshyn, Robert D. Technology as Symptom and Dream (London: Routledge, 1989) The author traces this yearning for corporeal departure to the Renaissance development of linear perspective. Linear perspective requires that the spectator detach himself from the world in order to visualize the line. Romanyshyn refers to man's venture into space as a logical continuation of this Renaissance development.

61 ibid p. 28

62 ibid p. 29
} 
In leaving the earth, we have, it seems, become more aware of it. Seen from outside the envelope of its protective atmosphere, seen from space, the earth can be seen, for the first time in the history of humanity, as home. And perhaps that is the most radical meaning of return: technology as homecoming. For it is only in leaving one's home, in departing from it, that the possibility of return arises. ${ }^{63}$

So in an ironic twist, technology can also bring about a longing for corporeal connectivity. It is through disconnection with the material world that we are pushed to reacquaint ourselves with our material condition and truly realize our corporeal oneness with the world. This theory of appreciation through absence goes some way to explaining the anxiety that telematic technology can bring about, when through its creative application, artists open themselves up to non-corporeal virtual realities.

As a counter to non-corporeal performance as promoted by the influential work of Phillip Auslander (discussed in the previous chapter), numerous writers within the field of performance art have pointed to corporeality as being central to the very notion of performance. Adrian Heathfield is one such author who has written about the importance of corporeal presence in contemporary performance:

Traditionally, the human body, our body, not the stage, is our true site for creation and materia prima. It's our empty canvas, musical instrument, and open book; our navigation chart and biographical map; the vessel for our ever changing identities; the centrepiece of the altar...Our body is also the very centre of our symbolic universe - a tiny model of human kind - and at the same time a metaphor for the larger socio-political body. ${ }^{64}$

Not surprisingly then, given the preceding discussion, it is through the advent of non-corporeal investigation ushered by the proliferation of digital performance

\footnotetext{
${ }^{63}$ ibid p. 203

${ }^{64}$ Heathfield, Adrian (ed.) Live: Art and Performance (New York: Routledge, 2004) p. 78
} 
works that such writing, aimed at reclaiming the importance of corporeal relevance, has become more prevalent and more desirous. As Romanyshyn has pointed out, it is through material absence that we crave for its return.

Corporeal appreciation through absence has also been noted in regard to acousmatic listening. Stacey Sewell writes of the absence of visual reference in acousmatic music as enticing the listener to focus not necessarily on the inherent sonic particulars of the sound object (as in Schaefferian reduced listening), but on the listener's own sense of embodiment. According to Sewell, 'the lack of a visible performer may turn the listener's attention back onto her own body'. ${ }^{65}$ Sewell refers to electroacoustic works that feature sound material where the biological body is referenced (inhalation of breath for example) as being particularly charged with this self-reflexive quality. In contrast to Pierre Schaeffer's transcendental phenomenology of transcendence through reduced listening, Sewell suggests that the acousmatic experience can create the opposite effect, enticing and encouraging us to reconnect with our own corporeality.

Returning to the topic of digitally mediatized performance, the body of the performer has an essential role to play in articulating the frame of reference in which technology exists. I agree with choreographer Johannes Berringer, who is experienced in the use of interactive multi-media, when he states that the body is necessary if only to enable the audience to gauge a sense of scale of the event:

The crucial limit or out-line in the theatre...is, the actor's body - the source of action, the place of articulation, where language, history, the world outside [bodiliness] is incorporated, where something will be shown that the

\footnotetext{
${ }^{65}$ Sewell, Stacey. 'Listening Inside Out: Notes on an embodied analysis' Performance Research: $A$ Journal of the Performing Arts (Vol 15 (3) 2010) p. 61
} 
spectator can perceive in reciprocal relation to the scale of proportion offered by the body. ${ }^{66}$

Again this is a vital aspect of acousmatic music, in which the human body is the spatial referent for implied and diffused sound, as Garry Kendall points out in an argument which bears clear relationship to Merleau-Ponty's corporeal phenomenology. Kendell alludes to the important role the body plays, on our perception of the spatial parameters in recorded music:

The deeply meaningful sense of space that is aroused when listening to electroacoustic music has its roots in a lifetime of embodied spatial experience. Beneath the apparent continuity of everyday space are the axes of the body giving structure and context to the experience of spatial events. ${ }^{67}$

Birringer (theatrical performance), Sewell, and Kendell (electroacoustic composition) are all intimately involved in working with digital technology to artistic ends. For them the body is an important point of reference in the realization of a digitally meditated working environment. This grounding of technology through the body is a key factor in enabling listeners and spectators to identify with digitally mediated art works. The body as an organizing metaphor, examples of which were given at the start of this chapter, can be seen as seeping into the realm of digitally mediated arts practices, not least as a way to pacify the anxiety that can occur when technology is foregrounded. What the research of Birringer, Sewell and Kendell shows us is that the intimate familiarity we have with our own bodies, our experience as bodily creatures in a fundamentally material world, shapes how

\footnotetext{
${ }^{66}$ Birringer, Johannes. 'Postmodern Performance and Technology', Performing Arts Journal, (26/27, 1985 pp. 221-233) Sourced from Govan Emma, Helen Nicholson and Katie Normington. Making a Performance: Devising Histories and Contemporary Practices (London: Routledge, 2007) p. 176

${ }^{67}$ Kendell, Gary. 'Spatial Perception and Cognition in Multichannel Audio for Electroacoustic Music' Organised Sound: An International Journal of Music Technology (Vol 15 (3) 2010) p. 231
} 
we discern both theatrical space and aural space. Our digitally meditated environment does nothing to negate this fact.

Perhaps the most convincing argument for the relevance of the material body in technologically mediated environments is that the physical body is the receptacle of all that we experience. The material human body is the mediator in terms of how we experience the world. The credence that Adrian Heathfield gives to the centrality of the human body in performance activity resonates with MerleauPonty's phenomenological take on the body (introduced in Chapter 6) as being the site through which all worldly experience is routed. Even when one negotiates with a digital avatar or enters into a virtual cyber world via computational connection, our reception of disembodied information, and the way we process it, is only made possible via the sensing organs of the body (eyes and ears for example) which are grounded in physicality.

A further trait of Merleau-Ponty's phenomenology, and one not yet discussed, which is of some significance regarding the importance of the body in contemporary art, is the notion that the body operates simultaneously as both subject and object. Elizabeth Grosz discusses the binary interchangeability of Merleau-Ponty's phenomenological body in her book Volatile Bodies. In the following quote she describes the entwined nature of mind and body as: ...both seeing and being seen, of touching and being touched, and of their intermingling and possible integration, a commonness in which both subject and object participate, a single "thing" folded back on itself. ${ }^{68}$

${ }^{68}$ Grosz, Elizabeth. Volatile Bodies: Toward a Corporeal Feminism (Indiana University Press, 1994) p. 95 
This ability of the body to be both subject and object, inside and outside, to be selfreflexive, bestows on the body a unique quality that is suited to the exploration of liminal subject matter. Liminality is concerned with the in-between states or regions of threshold where instability and ambiguity reside. Marina Abramovic, whose work I have already discussed, is an artist who has exploited the body as a means to foreground liminal themes. In an interview conducted by Peggy Phelan on the topic of performance methodology, Abramovic opines:

We are always in the space-in-between, like airports, or hotel rooms, waiting rooms or lobbies, gyms, swimming pools... all the spaces where you are not actually home. You haven't arrived yet... This is where your mind is most open. We are alert, we are sensitive, and destiny can happen. We do not have any barriers and we are vulnerable... This is for me the space from which my work generates. ${ }^{69}$

Liminality is explored in her performance Rest Energy (outlined in Chapter 6) regarding the amplified tension caused by the in-between-state of a bow primed for release. The taught bowstring and the arrow aimed at the artist's heart highlights the vulnerability of the corporeal subject. It is only via our intimate knowledge and empathy with the corporeal that we identify with the performer's apprehension. The body of each artist acts as both an instigator and recipient of this tension.

Regarding the relevance of the body in the context of electronically mediated art forms, I find the subject of liminality particularly interesting, because its investigation stipulates corporeal involvement in collusion with technology. In the introduction to her book Liminal Acts Susan Broadhurst alludes to the foregrounding of the corporeal in combination with media technology as important

${ }^{69}$ Heathfield (2004) p. 21 
tools in the investigation of the liminal. ${ }^{70}$ Broadhurst extols human corporeality as a source and site for the investigation of the intersemiotic. The idea of using the body as a means to bypass conventional language has proved a highly attractive proposition for those wishing to explore liminal realms, not least of all, those that exist beyond linguistic modes of communication. ${ }^{71}$

Recognizing the body's ability to communicate beyond verbal language anthropologist Jonathan Benthall writes:

...verbal language is merely one means whereby the body's physical organs and energies are articulated to convey meaning...If verbal language no doubt contributed substantially to the evolutionary success of early man, it may now be a part of the over-specialization of industrial man. The majesty we now see in verbal language... may have caused us to neglect the expressive resources of the body as a totality, to crush certain potentials within ourselves in the same way that we have crushed certain other cultures that appeared to us to be deficient in civilizing values. ${ }^{72}$

We can correlate the inhibitive factors of verbal language, as suggested by Benthall, with that of musical notation, which through its abstraction and closed structure as a system of signs and symbols referring only to musical qualities, is illequipped to reveal the audible nature of the liminal. By contrast, extramusical sound is well suited to exposing liminal regions as it is accepting of all sound, the expanded field, and corporeality. Noise, in particular, is ideally equipped to articulate in-between states. This is due to the very definition of noise as encompassing audible thresholds in the form of excessive amplitude, and severe

\footnotetext{
${ }^{70}$ Broadhurst (1999) p. 1

${ }^{71}$ The Viennese Actionists, discussed in Chapter 6 are regarded by Broadhurst as exemplars of liminal performance in that they exploited the body's non-linguistic powers of communication.

72 Benthall (1975) pp. 6-7
} 
dissonance (colored noise) for example. In this sense, noise is always provisional. It does not signify the realization of something, but rather a state of becoming. As Paul Hegarty declares in Noise/Music '[noise] can never realize itself, because any success means it has failed. Any outcome signals the end of noise.' 73

Noise is not a means to an end but suggests a lurching between poles and thus is ideal for implying the connective threads (liminal regions) of an ecological system. Noise can illuminate the expanded field in that it is unbounded by set parameters. Its morphology veers toward thresholds as a matter of course, disintegrating borders along the way. As Brandon LaBelle concurs:

...[noise] does not so much signal change, or announce the new, but rather occupies the space between. It directs the ear not to escape routes or alternatives, to 'complaints or suggestions' but to the mechanics at work in the system...

A contemporary example of a performance where both noise and the body are employed in an exploration of an 'audible liminal' is my performance work glitch body (2009) in which non-linguistic sonorities are brought forth from the depths of the human body and amplified in combination with electromagnetic interference caused by the strategic placement of transducers surrounding the performer. ${ }^{75}$ The performance does not strive for a musical outcome. Its audio/visual documentation instructs the viewer to watch the performance on continuous loop, serving to mask any beginning or end to the piece. The work does not intend to arrive or resolve. Its intention is to invoke an in-between condition and bathe in that condition perpetually.

\footnotetext{
${ }^{73}$ Hegarty, Paul. Noise/Music: A History (New York: Continuum, 2007) p. 146

${ }^{74}$ LaBelle (2006) p. 224

${ }^{75}$ See accompanying Creative Portfolio for glitch - body documentation.
} 
When we realize the potential of the body, as an intersemiotic sounding board, and position this in combination with modern technology, it offers the artist a sonically liminal situation, brought about by the tension caused when body and technology meet. As previously mentioned, the body and technology have an uneasy relationship, and this idea of the body and technology inhabiting the same space, is conducive to liminal foregrounding. The meeting of body and technology and/or their fusion offers the artist a tension-filled scenario in which in-between states can be exposed and investigated. Both noise and body in the study of the liminal, are therefore heralded as positive resources, welcome contaminants rather than pollutants. In this, and despite the fact that the physical body operates within a virtual field mediated by digital technology, our technological environment remains grounded in the corporeal. No matter how we try to entertain technology at the expense of the material body, corporeal influence is always in play. 


\section{CONCLUSION}

The rise of sound-as-art in twentieth-century art practice can be attributed to the foregrounding of noise and human corporeality within the context of an expanded field. The twentieth-century conception of an expanded field shattered the idea of the traditional autonomous artwork (as being framed, separate from real life), allowing for, among other things, the inclusion of the human body and noise as part of the artistic experience.

The twentieth-century avant-garde, with its desire to merge art with life, and low art with high art, encouraged multi-disciplinary and multi-media experimentation. Avant-garde activity succeeded in advancing the idea of an expanded field. The post-World War II neo-avant-garde, led by John Cage, addressed the aural aspect of the field to include all sounds (prefigured by Luigi Russolo). Cage's belief that all sounds could be music signalled the arrival of noise and the sonorous body as art making materials. During the 1950s and 1960s acousmatic composition emerged, offering an alternative to the corporeally inclusive sound art embraced by Cage. Non-corporeal sonic art as championed by Pierre Schaeffer followed the transcendental paradigm of the established musical arts, in that its goal was to create a transcendental experience for the listener. In contrast, corporeal sound art moved outwards into the physical world in search of immanence via a material and conceptual investigation of the expanded field.

Despite the popularity of the non-corporeal sonic art aesthetic, not least of all within academia, the corporeally inclusive sound-as-art trivium was nurtured by 
visual artists and performance artists during the 1960s and 1970s. Within the visual and non-musical performing arts sound became valued more and more for its extramusical properties.

The 1980s brought forth a renewed enthusiasm for non-corporeal sound-based art, due to the digital revolution expanding non-corporeal concerns beyond the studio into the performance arena. However, during the late 1980s and throughout the 1990s, performance artists such as Stelarc and Laetitia Sonami saw the body as a means through which digital technology could be applied and realized. Bringing these worlds together, these artists succeeded in creating man-machine hybrid instruments.

The work of Stelarc and Sonami serves to illustrate that the traditional distinctions between human performer and technology (between the ideologies of Schaeffer and Cage) need not be considered as isolated from each other. In Stelarc's Third Hand performance and Sonami's 'Lady's Glove', body and technology are intertwined. In my opinion, it is the matrix of connectivity and the tension created between the organic, mechanical and cyber worlds that are the most enticing and engaging aspects of contemporary sound-based performance. For the sound artist of the twenty-first century, both the physical human body and technology can be viewed as enfolding into one another, something that is aptly representative of technology's embeddedness within the social and physical infrastructure of our global community. In taking Romanyshyn's views into account regarding appreciation through absence, the body can be seen as being even more relevant, the more mediatized our environment becomes. 
The ability of the body to represent many things simultaneously, as a conduit for the mental, corporeal and environmental, places the body at the forefront of future artistic research, not only in sound-based art but across many disciplines. Furthermore, adopting the concept of an expanded field whose borders are always in flux, the body distinguishes itself as our one true constant. The body presents a grounded context — in the phenomenological round — located within a constantly changing environment which confronts the, as yet, immutable fact of our corporeality. In exploring sound outside the accepted coded norms of musicality and visual symbolism, the human body can serve as an important familiar. Its presence and agency, better enables us to venture forth into the unfamiliar, providing a point of reference and return through which we can more fully explore what is as yet unknown. We are living in a historical period where the boundaries between technology and the corporeal are breaking down, and in which the corporeal and non-corporeal are becoming increasingly interchangeable. Within this context the traditional pluralistic distinctions between body and technology, can be approached as complementary couplings, presenting us with an enticing prospect for the future of sound in the arts. 


\section{BIBLIOGRAPHY}

Artaud, Antonin. The Theatre and Its Double: Essays, (trans.) Victor Corti Montreuil (London: Calder, 1970)

Attali, Jacques. Noise: The Political Economy of Music. (Minneapolis: University of Minnesota Press, 1985)

Auslander, Philip. Liveness: Performance in a Mediatized Culture (New York: Routledge, 1999)

Bailes, Sara Jane. Performance and the Poetics of Failure (New York: Routledge, 2011)

Barthes, Roland. The Death of the Author (1967) published in Critical Essays (trans.) Richard Howard (Evanston [III]: Northwestern University Press, 1972)

Baudrillard, Jean. Simulacra and Simulation (trans.) Sheila Faria Glaser (Ann Arbor: University of Michigan Press, c1994)

Birringer, Johannes. 'Postmodern Performance and Technology' Performing Arts Journal (Vol 9 (2/3) 1985, pp. 221-223)

Broadhurst, Susan. Liminal Acts: A Critical Overview of Contemporary Performance and Theory (London: Cassell, 1999)

Broadhurst, Susan and Josephine Machon. (eds.) Performance and Technology: Practices of Virtual Embodiment and Interactivity (New York: Palgrave Macmillan, 2006)

Cage, John. Silence (Middleton, Connecticut: Wesleyan University Press, 1961)

Carlson, Marvin. Performance: A Critical Introduction (London: Routledge, 1996)

Carr, C. On Edge: Performance Art at the End of the Twentieth Century

(Connecticut: Wesleyan University Press, 2008)

Cascone, Kim. Comatonse Recordings: Articles \& Reviews. Computer Music Journal (Vol 24 (4) 2000, pp. 91-94)

Clarke, Eric F. Ways of Listening: An Ecological Approach to the Perception of Musical Meaning (New York: Oxford University Press, 2005)

Collins Nick, Julio d'Escrivan. The Cambridge Companion to Electronic Music (Cambridge: Cambridge University Press, 2007) 
Croft, John. 'Theses on liveness', Organised Sound: An International Journal of Music Technology (Vol 12 (1) 2007, pp. 59-66)

Emmerson, Simon. Living Electronic Music (Burlington, Vt.: Ashgate, 2007)

Ferrer, Rafael. 'Embodied Cognition Applied to Timbre and Musical Appreciation: Theoretical Foundation'.

- http://www.bpmonline.org.uk/bpm10/ferrer_rafael-

embodied_cognition_applied_to_timbre_and_musical_appreciation_theoretical_fo undation.pdf (accessed May 2012)

Gann, Kyle. No Such Thing as Silence (New Haven: Yale University Press, 2010)

Gere, Charlie. Art, Time and Technology (New York: Berg, 2006)

Govan Emma, Helen Nicholson and Katie Normington. Making a Performance:

Devising Histories and Contemporary Practices (London: Routledge, 2007)

Gritten, Anthony and Elaine King. (eds.) Music and Gesture (Aldershot, England: Ashgate, c2006)

Grosz, Elizabeth. Volatile Bodies: Toward a Corporeal Feminism (Bloomington: Indiana University Press, 1994)

Benthall, Jonathan and Ted Polhemus. (eds.) The Body as a Medium of Expression (London: Penguin Books Ltd, 1975)

Gold Sarah, Karlyn de Jongh, Peter Lodermeyer. Personal Structures: Time Space Existence (Koln: DuMont, 2009)

Gunter, Berghaus. Avant-garde Performance: Live Events and Electronic Technologies (New York: Palgrave Macmillan, 2005)

Hahn, Tomie. Sensational Knowledge: Embodying Culture through Japanese Dance (Middletown: Wesleyan University Press, 2007)

Heathfield, Adrian. (ed.) Live: Art and Performance (New York: Routledge, 2004)

Hegarty, Paul. Noise/Music: A History (New York: Continuum, 2007)

Hein, Nina. 'Body Imagery in the Avant-gardes of the twentieth Century' Body, Space and Technology Journal (Vol 9 (2) 2010)

http://people.brunel.ac.uk/bst/vol0902/home.html (accessed May 2012)

Ihde, Don. Listening and Voice (Athens, Ohio: Ohio University Press, 1976)

Ihde, Don. Experimental Phenomenology: An Introduction (New York: Capricorn, 1977) 
Jones, Amelia. STELARC, The Monograph, Marquard Smith (ed.) (Massachusetts: MIT Press, 2005)

Jones, Caroline A. (ed.) Sensorium: Embodied Experience, Technology, and Contemporary Art (Cambridge: MIT Press, 2006)

Joseph, Branden. W. Beyond the Dream Syndicate: Tony Conrad and the Arts after Cage (Brooklyn, New York: Zone Books, c2008)

Kahn, Douglas. Noise, Water, Meat: A History of Sound in the Arts

(Massachusetts: MIT Press, 2001)

Kane, Brian. 'L'Objet Sonore Maintenant: Pierre Schaeffer, sound objects and the phenomenological reduction' Organised Sound: An International Journal of Music Technology (Vol 12 (1) 2007, pp. 15-24)

Kendell, Gary. 'Spatial Perception and Cognition in Multichannel Audio for Electroacoustic Music' Organised Sound: An International Journal of Music Technology (Vol 15 (3) 2010, p. 228-38)

Kim-Cohen, Seth. In the Blink of an Ear: Toward a Non-Cochlear Sonic Art (New York: Continuum, 2009)

Kozel, Susan. CLOSER: Performance, Technologies, Phenomenology (Cambridge, Massachusetts: MIT Press, 2007)

Krauss, Rosalind. 'Sculpture in the Expanded Field', October (Vol 8 (Spring) 1979, pp. 30-44)

LaBelle, Brandon. Background Noise: Perspectives on Sound Art (New York: Continuum, 2006)

Leitner, Bernhard. http://www.archdaily.com/168979/bernhard-leitner-soundspaces/ (accessed April 2012)

Merleau-Ponty, Maurice. Phenomenology of Perception (trans.) Colin Smith (London: Routledge and Kagan Paul, 1962)

Riddoch, Malcolm. http://malcolmriddoch.com/ (accessed May 2012)

Romanyshyn, Robert D. Technology as Symptom and Dream (London: Routledge, 1989)

Russolo, Luigi. The Art of Noises published as a booklet by Direzione del Movimento Futurista, Milan, 1 July 1913. Sourced from Apollonio, Umbro. (ed.) Futurist Manifestos (London: Thames and Hudson, 1973)

Rutsky, R. L. High Techne: Art and Technology from the Machine Aesthetic to the Posthuman (Minneapolis: University of Minnesota Press, 1999) 
Salter, Chris. Entangled: Technology and the Transformation of Performance (Cambridge, Massachusetts London: MIT Press, 2010)

Sandford, Mariellen R. (ed.) Happenings and Other Acts (New York: Routledge, 1995)

Sawday, Jonathan. The Body Emblazoned: Dissection and the Human Body in Renaissance Culture (London: Routledge,1995)

Schaeffer, Pierre. Traitë des objets musicaux (Paris: editions du Seuil, 1966)

Schulz, Bernd. (ed.) Aspekte der Klangkunst = Resonances: aspects of sound art (Heidelberg: Kehrer, 2002)

Sewell, Stacey. 'Listening Inside Out: Notes on an embodied analysis'

Performance Research: A Journal of the Performing Arts (Vol 15 (3) 2010)

Smalley, Denis. 'Spectromorphology: explaining sound shapes' Organised Sound: An International Journal of Music Technology (Vol 2 (2) 1997, pp. 107-126)

Soanes Catherine, Angus Stevenson. (eds.) Concise Oxford English Dictionary Eleventh Edition (Oxford: Oxford University Press, 2004)

Sonami, Laetitia. http://www.sonami.net/works/ladys-glove/ (accessed April 2012)

Stelarc, Obsolete Body, http://www.stelarc.va.com.au/obsolete/obsolete.html (accessed May 2012)

Sterne, Jonathan. The Audible Past: Cultural Origins of Sound Production (Durham: Duke University Press, 2003)

Sutton Damian, Susan Brind, Ray McKenzie (eds.) The State of the Real: Aesthetics in the Digital Age (London: I. B. Tauris, 2007)

Vitruvius, Pollio. De Architectura (trans.) Richard Schofield. (London: New York: Penguin, 2009)

Warr Tracy, Amelia Jones. The Artist's Body: Themes and Motives (ed.) Tracy Warr; (survey) Amelia Jones (London: Phaidon, 2000)

Wishart, Trevor. On Sonic Art (Amsterdam: Harwood Academic Publishers, 1996) 
Creative Portfolio 


\section{PORTFOLIO CONTENTS}

Introduction

p. 76

\section{Resonant Body}

glitch - body (2'38')

p. 78

sensate (1'36")

p. 80

sensate extra (4'02”)

persona elemental (14'02”)

p. 82

persona elemental extra (1'52')

Magnetic Picnic (15’34”)

p. 84

Magnetic Picnic extra (5'30”)

\section{Implied Body}

Silver (2'46”)

p. 86

The Dissonant Fisherman

p. 88
1 (.44”)
2 (1'49')
3 (3'38')
4 (4'11") 


\section{INTRODUCTION}

The works in this portfolio are focused on exposing the material human body as a site for the manifestation and transduction of elemental sonorities. Fundamentally, the works featured here do not strive for a musical outcome, but rather sound is used as a means to articulate physical space and corporeal presence.

The portfolio is presented in two sections: Resonant Body and Implied Body. Performances in the former are focused on investigating the corporeal nature of the performing body, whilst the later explores notions of body trace, as opposed to an overt representation of the corporeal.

The technology I have employed throughout this portfolio consists primarily of piezo transducers and small amplification units. My reasons for employing this simple technology is that I do not want the technology to overtake the body, or more to the point, I do not want the technology to distort the centrality of the body. I have incorporated a very basic technology that serves to amplify, and preserve to a large extent, the raw sounds of the body, with the aim of magnifying corporeal presence.

I regard the audio/visual presentations in this portfolio as compositions in the wider sense of the word, in that they represent a composite ordering of materials. These materials include sound, light, amplified architecture, resonant objects, and the spaces between objects. These elements are utilized in such a way as to allow for an extension or integration of the corporeal as part of an expanded field. 
Juxtaposed edits are a strong feature of the portfolio documentation. The cut and paste editing style is intended to draw attention to the recording media itself, as well as alluding to a sense of disjointed temporality. This 'glitch' style of documentation is also intended to render a visual representation of noise as an artistic material prone to disruption. It is important, however, that the documentation be recognized as such, that it cannot fully stand in for the original performances and thus has been shaped to convey qualities of direct experience, the intensity of liveness in particular, that are lost in the process of mediation. 


\section{glitch - body}

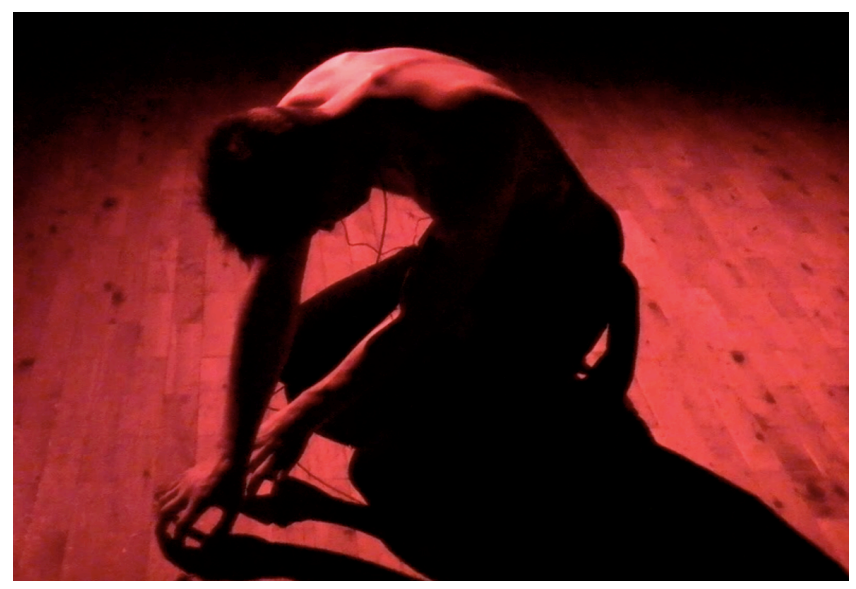

The performance work glitch - body addresses the notion of the performing body as a resonant object capable of channelling and transducing electronic sound.

For this performance several piezo transducers were attached to the skin of the performer (on the throat and heart), amplifying both interior and exterior body activity. Amplification units and FM receivers were placed around the perimeter of the performance space. The amplification units and FM receivers in combination with the piezo transducers, served to amplify and disperse radio frequencies throughout the auditorium. During the performance, the performer interacts with the audible electromagnetic field, initiating improvised body movements sensitive to the unstable nature of the sonic environment.

Noise, generated from electricity that is filtered through the body, contains an element of body trace that communicates in a very direct way the presence of the animate body, both interior and exterior, and forces us to think about the role the 
body plays in our eco-systemic sound environment.

The edited footage condenses the live work with the aim of intensifying the notion of the body as being in an in-between state, both sonically (due to the noise material) and temporally. The exhibition context for this short edited work is intended for a gallery wall and the playback is to be looped so that there is no start or end to the piece.

The piezo disc configuration featured in glitch - body concerning attachments to the heart and throat, is also employed in the following study sensate, and the performance piece persona elemental. 


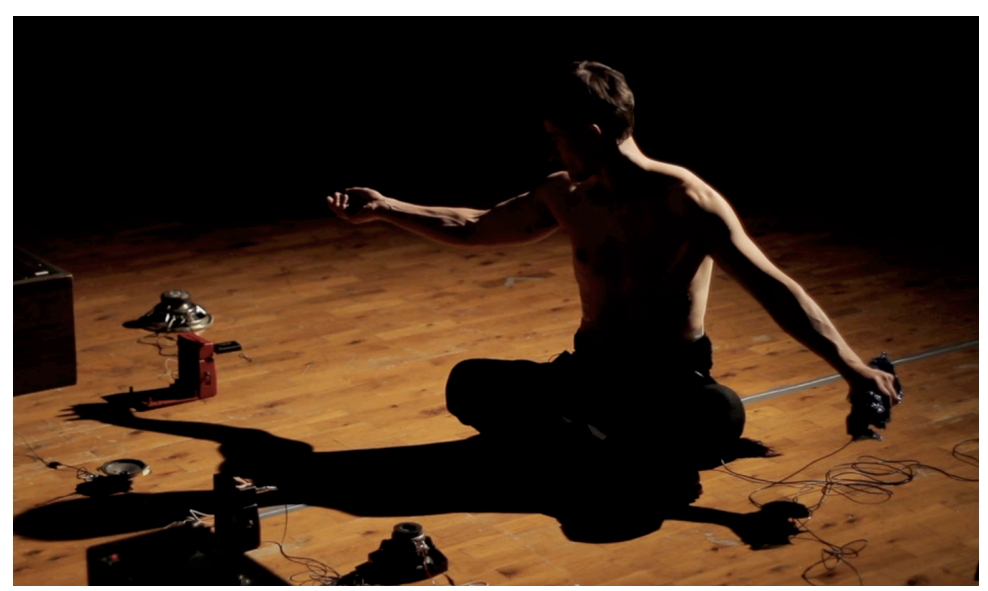

sensate and can be considered an extension of glitch - body in that amplifiers, and FM receivers were strategically placed around the performance space. However, in this piece the amplification units were positioned closer to the body, heightening the possibility of unforeseen amplifier distortion. This demanded a more nuanced approach from the performer.

The stage arrangement included several speaker bins connected in series with the speaker cones hard pressed against the floor. Audio sourced from the interior of the amplified body was transmitted (via the speaker bins) directly into the floorboards, effectively transforming the floor into an expansive speaker interface. Separate transducers attached to the floorboards, in turn, picked up the vibrations from the speaker bins, further amplifying the audio signal. Thus, a regenerative feedback loop was created, through the amplified material body of the performer melding with the amplified architectural space. 
As in glitch - body, the body of the performer takes a central position. An audible electromagnetic field is created. The performer, via subtle body movements, must negotiate the electrified spatial field; a field susceptible to unpredictable bursts of resonant feedback.

Everyday objects such as an amplified piece of blue cellophane and a transistor radio were experimented with, as a way to further distort the all-encompassing electromagnetic field with a more explicit representation of human agency. A microphone inside the mouth cavity was also employed in an attempt to reveal the mouth as a resonant chamber (refer to the opening scene in sensate extra). 


\section{persona elemental}

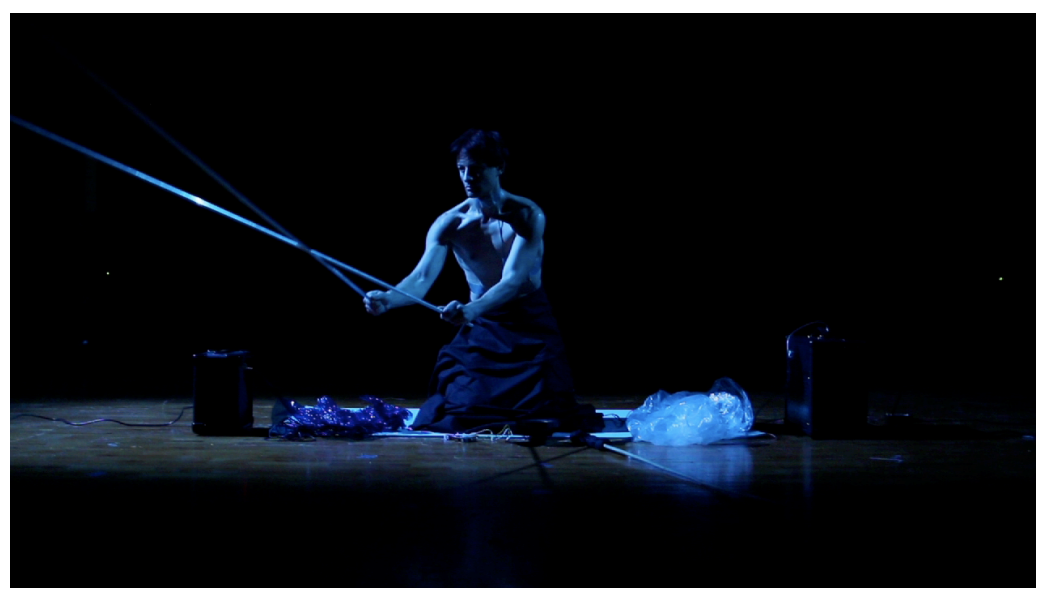

persona elemental incorporates some of the ideas gleaned from the more experimental study of sensate in the creation of a structured narrative piece for public performance. For this piece a more stable environment was constructed in contrast to glitch - body and sensate. Audible electronic feedback was minimized and the audio generated was designed to produce sound events in direct correlation to performance gesture.

Conscious of the listeners propensity to discern which sounds are acoustically generated and what sounds are digitally and/or electronically modified or enhanced, digital processing was used sparingly (with the vocals being an exception) in order not to distract from the raw elemental sounds produced by the metallic poles, radio static, and amplified breath.

The vocalizations uttered by the performer were not intended to be legible. During 
the performance the audience is enticed to struggle in the discernment of textural clarity. Occasionally individual words can be made out, at other times not. The aim of this approach was to draw attention to the sound of the voice (in combination with electronic enhancement), as opposed to a semantic interpretation of the words themselves.

Slow gestures were favored for this performance, with the pace of the sequence of events guided by the pulse of the performer's amplified heartbeat. This was punctuated with rapid increases in tempo (the swinging pole for example). The overriding slow nature of the piece directs the viewer to focus more intently on the mechanics of body movement. 


\section{Magnetic Picnic}

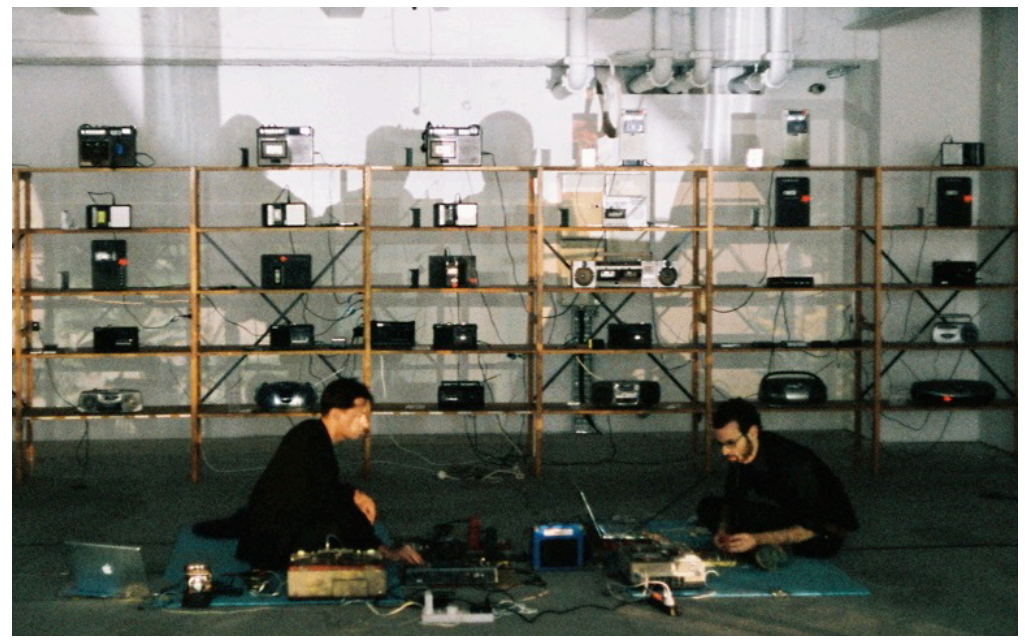

Magnetic Picnic was performed in collaboration with sound artist Richard

Robertshawe. This piece was improvisational with the instructions being that each performer attempt to enfold sound sources such as analogue tape loops, digital samples, and the real-time amplification of everyday objects into a cohesive multilayered sound continuum.

Within this continuum an exposed circuit board (from a Casiotone electronic keyboard) was used to demonstrate the human body's penchant for electrical transduction. Many sound sources were utilized in this performance and the circuit board interface does not feature in the main performance document (Magnetic Picnic) until 4'25'. A close up extensive demonstration of this interface is provided in the Magnetic Picnic extra .mov file. 
The performers fingers act as bridges between the components on the circuit board, altering resistance values and other set parameters. The fixed keyboard and switch controls of a Casiotone electronic keyboard are designed to limit and control what the instrument can do. However, through interacting directly with the circuit board, the electronic keyboard is transformed into an unstable instrument, resulting in sonic outcomes that are unpredictable. As with glitch - body and sensate the performance is reflexive. The performer listens to the improvised sonic result, and instinctively works his way through the performance, using hand and finger pressure to explore sonorous zones of interest. 


\section{Silver}

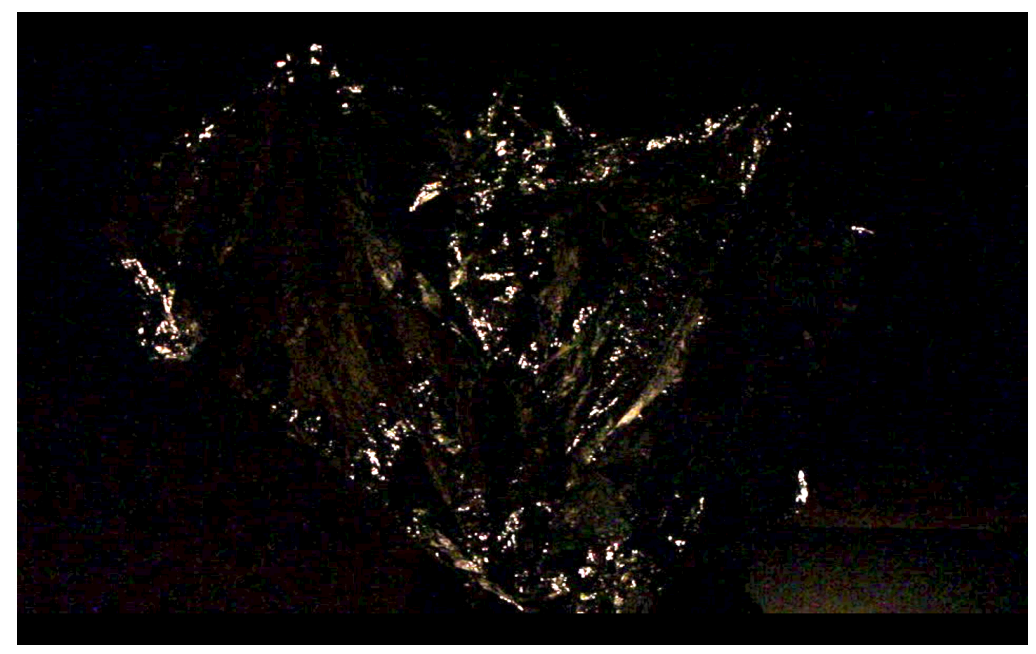

Silver explores the idea of appreciation through absence (as discussed in Chapter 8 of my thesis). When viewed in this conceptual light, the idea of the corporeal exists, not only via its implication in the physical materials used but by virtue of its absence.

The technology used in this piece is simply a piezo disc attached to a piece of silver foil. In this work a human performer situated beneath the material, animates the foil. The intended subject of the performance - the implied body-is enhanced through the documentative process. Audio is present for the first half of the document, followed by no audio during the second half. This sudden absence of audio from 1'22" until the end of the piece is intended to stir the memory of the spectator. What did we hear before the silence? Does the silent version portray a different illusion of corporeality than the audible version? For example, do we concentrate more intently on the hard-to-make-out humanoid shape beneath the foil when we view the moving image with no audible reference? And does the 
inaudible version speak differently as a result of us knowing that there is a separate audible version in existence?

Although sound plays a minimal role in this piece, I feel that the piece as a conceptual whole is stronger, through sound being used sparingly. The noisy grain of the sound produced by the silver foil masks a clear gesture to sound correlation, in that, for example, a sweeping movement of the arm does not differ sonically from a slow turn of the head. On the surface, it may appear that the corporeal has no place in such a work where the literal human body is intentionally obscured. But human agency (in the form of a human figure) can be easily traced in the shifting movements of the foil. So the trace in this piece is all-important, as opposed to a direct presentation of the human body. 


\section{The Dissonant Fisherman}

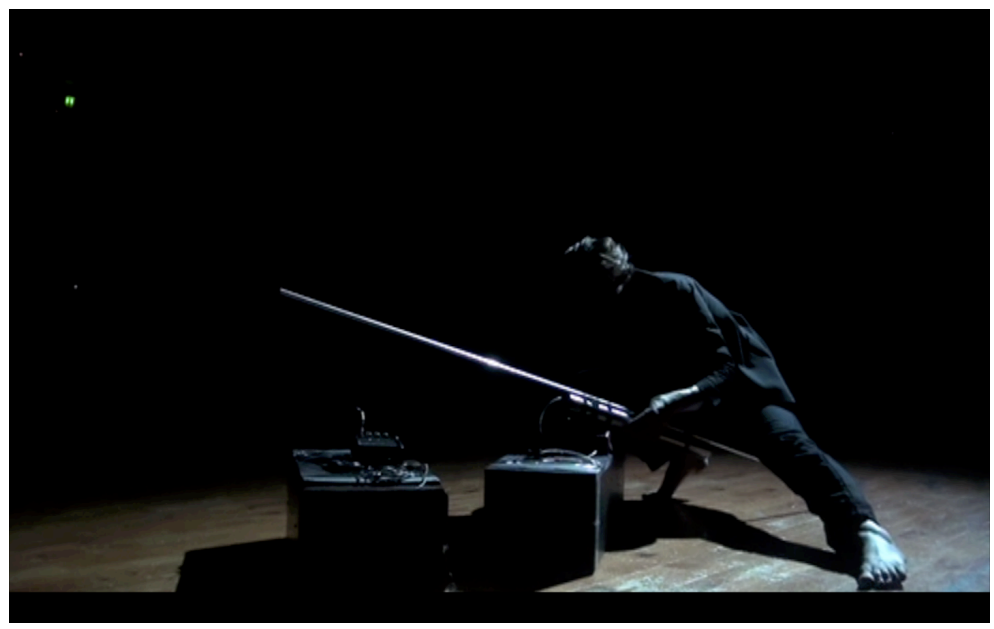

The Dissonant Fisherman combines the amplified architectural environments of glitch - body and sensate with the theatricality of persona elemental and the implied body idea of Silver.

As the title suggests, this work is an improvised performance where the performer attempts to fish for sonorous dissonance. In this performance an FM transmitter is attached to a metal rod. Electronic feedback is induced and partially controlled by the movement of the metal rod in relation to two mobile speaker boxes. Attached to the top of the speaker boxes rest two FM receivers and a compact microphoneto-amplifier feedback circuit. In effect, the two speaker boxes are crude noise generators. The positional relationship between the speaker bins and the hand held metal rod is key to the sonic transmission of sound material within the performance space. The performer can attempt to induce (fish for) electromagnetic interference by either altering the position of the speakers by dragging them or by moving the 
metal rod. The audio in this piece does not imply the body directly, but rather it implies the aural spatial field that exists between the performer (holding the FM transmitter) and the speaker bins (to which the FM receivers are attached).

The document of this performance is split into four separate .mov files in order to portray numerous perspectives on the singular performance. As with Silver, the documentative process itself plays a fundamental role in articulating the artistic concerns of the piece.

\section{The Dissonant Fisherman $1 \& 2$}

The edited camera footage suggests that the performance area extends beyond the bounds of the camera frame. The performers body often leaves the frame yet is implied by the continuation of sound caused by the dragging of speaker boxes.

\section{The Dissonant Fisherman 3}

The simple technology of string, and light as a compositional element communicate corporeality when the body is visually absent. The taught string represents the stored energy that exists between the sound emitting object (speaker boxes) and the body of the performer. The taught string implies the agency of a performing body (in the absence of the visual body) just as the kinetic silver foil in Silver implies corporeal presence. 


\section{The Dissonant Fisherman 4}

Although the literal body of the performer barely enters the camera frame, we can identify with the human body via its shadow, extending the notion of appreciation through absence as explored in Silver.

All four .mov files show the simple elements of light, string, amplified noise, and creative camera work to illustrate that the literal appearance of the material body is not necessary for the audience to register a corporeal connection.

Furthermore, the documentation of the live act articulates this realization, perhaps even more effectively than if one were to witness the actual performance in realtime, in that the seated spectator would have only one view of the creative act during the live performance. By viewing four versions of the singular event, the artist is able to accentuate the conceptual nature of the work more effectively (after the event). I want to make it clear that I do not wish to devalue the importance of the live act, but merely wish to point out that the person behind the camera can also be looked upon as a performer of sorts, particularly when, in our current age of media saturation, more people are likely to view the documentation of the live event rather than experience the live event itself.

Through the documentation of The Dissonant Fisherman the camera operator and the film editor succeed in enfolding real-time footage to intensify the performative act, presenting a secondary performance, to complement the original performance experienced in the live. 
